\title{
Detailed Analysis of the Solution Heat Treatment of a Third-Generation Single-Crystal Nickel-Based Superalloy CMSX-10K ${ }^{\circledR}$
}

\author{
HON TONG PANG, NEIL D'SOUZA, HONGBIAO DONG, HOWARD J. STONE, \\ and CATHERINE M.F. RAE
}

A detailed analysis of the response of as-cast third-generation single-crystal nickel-based superalloy CMSX-10K ${ }^{\circledR}$ to solution heat treatment $(\mathrm{SHT})$ has been carried out, alongside an SHT optimization exercise. The analysis was conducted through microstructural characterization, differential scanning calorimetry, and compositional homogeneity measurements, quantifying (i) the dissolution and microstructural evolution of the inter-dendritic constituents, (ii) the shift in thermo-physical characteristics of the material, and (iii) the change in compositional homogeneity across the microstructure, in order to gain further understanding of these phenomena during the progression of the SHT. During the early stages of SHT, the coarse cellular $\gamma^{\prime} /$ narrow $\gamma$ channel inter-dendritic constituents which were the last areas to solidify during casting, progressively dissolve; homogenization between these inter-dendritic areas and adjacent dendritic areas leads to a rapid increase in the incipient melting temperature $T_{\mathrm{IM}}$. The fine $\gamma / \gamma^{\prime}$ morphology which were the first inter-dendritic constituents to solidify after primary $\gamma$ dendrite solidification were found to progressively coarsen; however, subsequent dissolution of these coarsened $\gamma / \gamma^{\prime}$ inter-dendritic areas did not result in significant increases in the $T_{\text {IM }}$ until the near-complete dissolution of these inter-dendritic areas. After the final SHT step, residual compositional micro-segregation could still be detected across the microstructure despite the near-complete dissolution of these remnant inter-dendritic areas; even so the $T_{\mathrm{IM}}$ of the material approached the solidus temperature of the alloy.

DOI: $10.1007 / \mathrm{s} 11661-015-3252-2$

(C) The Author(s) 2015. This article is published with open access at Springerlink.com

\section{INTRODUCTION}

SINGLE-CRYSTAL nickel-based superalloys continue to be the material of choice for turbine blades which experience among the most demanding conditions in gas turbine engines. With the ever increasing demands of greater engine efficiencies, new generations of alloys which possess improved mechanical properties and environmental resistance performance have been developed continuously. This development has resulted in progressively higher levels of dense refractory elements such as Mo, Ta, W, and Re in the alloys; the level of refractory alloying elements ( $\mathrm{Mo}+\mathrm{Ta}+\mathrm{W}+\mathrm{Re})$ in 1st (e.g., CMSX-3), 2nd (e.g., CMSX-4) and 3rd generation (e.g., CMSX-10) alloys have increased from about $14 \mathrm{wt}$ pet to approximately $16.5 \mathrm{wt}$ pet and then to greater than $20 \mathrm{wt}$ pct. ${ }^{[1,2]}$

HON TONG PANG, Senior Technical Officer, HOWARD J. STONE, Assistant Director of Research, and CATHERINE M.F. RAE, Professor, are with the Department of Materials Science and Metallurgy, University of Cambridge, 27 Charles Babbage Road, Cambridge CB3 0FS, U.K. Contact e-mail: htp21@cam.ac.uk NEIL D'SOUZA, Casting Specialist, is with Rolls-Royce plc., P.O. Box 31, Derby DE24 8BJ, U.K. HONGBIAO DONG, Professor, is with the Department of Engineering, University of Leicester, University Road, Leicester LE1 7RH, U.K.

Manuscript submitted June 8, 2015.

Article published online December 1, 2015
The superior high-temperature mechanical properties of Ni-based superalloys arise from the ordered $\mathrm{L}_{2}$ precipitate $\gamma^{\prime}$, which forms a coherent interface with the $\gamma$ matrix phase. ${ }^{[10,11]}$ The strength is derived from the fact that it is difficult for dislocations to penetrate $\gamma^{\prime}$ precipitates, coupled with the high constraint imposed by the $\gamma$ matrix channels of only 40 to $80 \mathrm{~nm}$ in width. ${ }^{[12]}$ During casting to obtain single-crystal turbine blades, primary $\gamma$ dendrite solidification is accompanied by solute partitioning at the solid-liquid interface. This leads to the formation of a non-equilibrium inter-dendritic constituent in the as-cast microstructure and results in significant elemental segregation across the microstructure. ${ }^{[3-9]}$ The non-equilibrium inter-dendritic constituents must be dissolved and the compositional inhomogeneities must be minimized to attain a uniform and cube morphology of the $\gamma^{\prime}$ precipitates to ensure optimal high-temperature properties. As such, the as-cast microstructure has to be homogenized via solution heat treatment (SHT) prior to service. The increased refractory element contents in newer generation alloys result in sluggish solute diffusion both during solidification and SHT, leading to more highly segregated as-cast microstructures and consequently the need for higher temperatures, longer soak times and complexity of the SHT cycles to provide effective homogenization while avoiding the occurrence of incipient melting. Typical commercial SHT cycles for three 


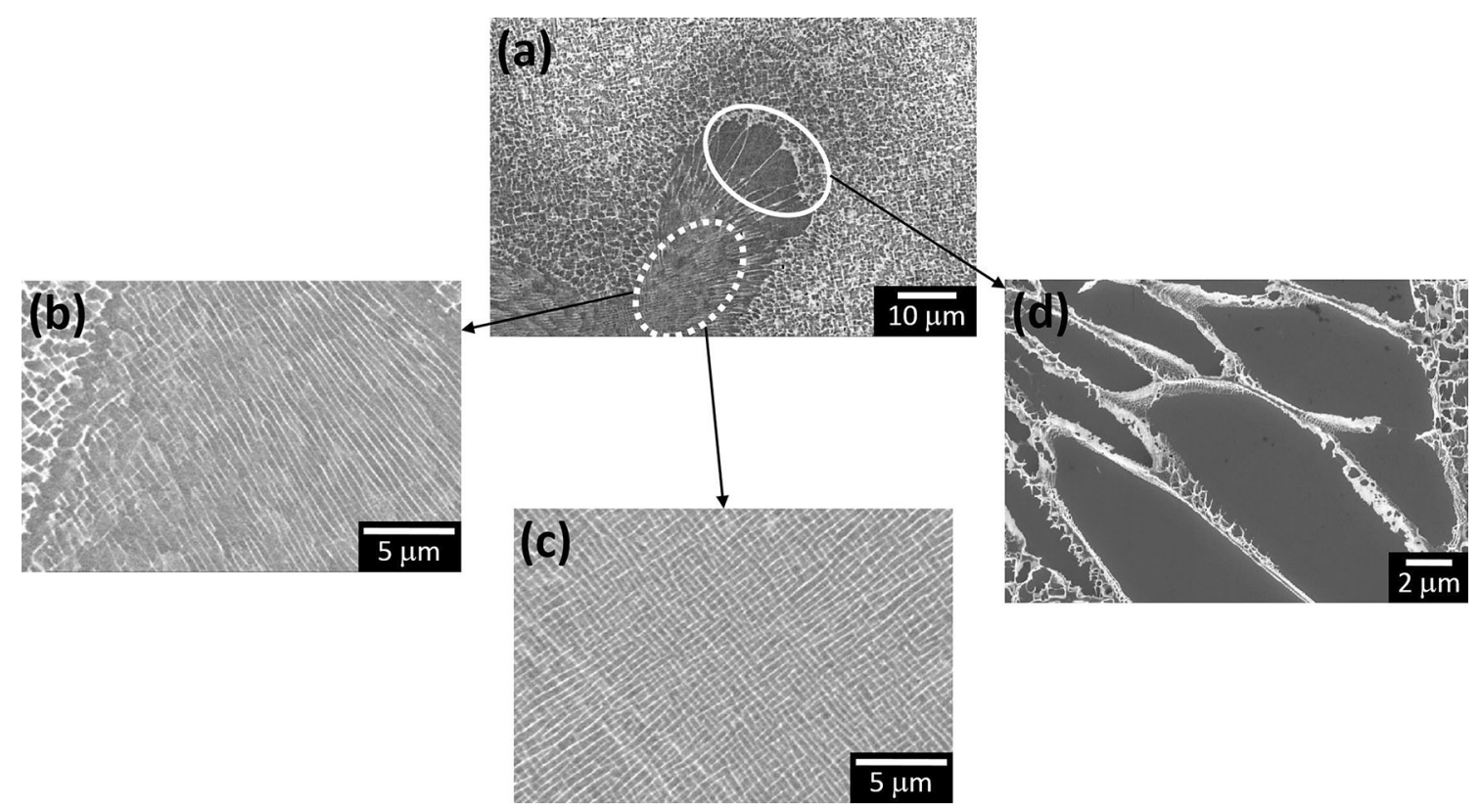

Fig. 1-Microstructure of the inter-dendritic regions of as-cast CMSX-10K (a) overview of the inter-dendritic region, $(b)$ and $(c)$ fine $\gamma / \gamma^{\prime}$ morphology, $(d)$ coarse cellular $\gamma^{\prime}$ separated by narrow $\gamma$ channels. ${ }^{[4]}$

generations of single-crystal nickel-based superalloys are summarized in Reference 2.

The increasingly demanding SHT requirements of newer generations of alloys result in significant increases in cost. In order to optimize the SHT, an understanding of the response of the as-cast microstructure during the progression of SHT is required. Most of the previous studies on SHT have primarily focussed on the dissolution of the inter-dendritic regions or the compositional homogeneity attained after SHT..$^{[2,3,13-15]}$ However, less attention has been paid to changes in the thermo-physical characteristics of the material as well changes within the microstructure as a function of SHT progression. The thermo-physical characteristics specifically refer to the temperatures over which phase transformations occur; in the current study the primary interest is the incipient melting temperature of the inter-dendritic constituents. $^{[16,17]}$ There has also been little explanation of the underlying mechanisms controlling the various changes observed. Notably, a detailed study carried out by Fuchs ${ }^{[2]}$ highlighted the changes in the thermo-physical characteristics, inter-dendritic area fraction, and elemental segregation as a function of SHT progression; however, these observations were not rationalized in detail against the changes within the microstructure.

The inter-dendritic regions of as-cast CMSX-10K have been shown to consist of two distinct morphologies, details of which have been presented in our earlier study ${ }^{[4]}$ and for the sake of brevity, the main points are summarized. The two morphologies are (i) fine $\gamma / \gamma^{\prime}$ as shown in Figures 1(b) and (c), and (ii) coarse cellular $\gamma^{\prime}$ separated by narrow $\gamma$ channels as shown in Figure 1(d). The fine $\gamma / \gamma^{\prime}$ morphology consists of elongated cuboidal $\gamma^{\prime}$ separated by thin lamellae of the $\gamma$ phase; the typical width of the elongated $\gamma^{\prime}$ is approximately $300 \mathrm{~nm}$. The coarse cellular $\gamma^{\prime}$ /narrow $\gamma$ channel morphology widths are typically up to tens of microns. Following detailed examination of the two distinct morphologies, it was deduced that after primary $\gamma$ dendrite solidification, solidification of the inter-dendritic region commences on the periphery of the dendrite lobe to form areas showing the fine $\gamma / \gamma^{\prime}$ morphology. This grows into the segregated liquid, followed by a gradual transition to the formation of the coarse cellular $\gamma^{\prime} /$ narrow $\gamma$ channel morphology up to the terminal stages of solidification where they impinge on adjacent dendrite lobe peripheries or onto cellular $\gamma^{\prime}$ structures growing from a neighboring inter-dendritic pool. These inter-dendritic areas with different morphologies solidify over a temperature range. The fine $\gamma / \gamma^{\prime}$ morphology areas are the first to form at higher temperatures followed by the formation of the coarse cellular $\gamma^{\prime}$ morphology areas at lower temperatures up to the end of the solidification process.

In light of the detailed findings pertaining to the microstructure and solidification sequence of the inter-dendritic regions, ${ }^{[4,6]}$ there was a distinct lack of information in the literature which relates the effects of SHT as well as the associated changes in e.g., the thermo-physical characteristics and elemental segregation to these microstructural features. The effectiveness of any given SHT is expected to be primarily governed by its effects on the microstructure of the inter-dendritic regions. Therefore, an in-depth understanding of the underlying changes to the microstructure of the inter-dendritic areas and its associated effects on the thermo-physical characteristics, elemental segregation, etc. during the progression of the SHT is required in order to optimize the SHT. In this study, detailed analyses of the response of the as-cast microstructure at various stages of the SHT were carried out in a typical 
Table I. Composition (Weight Percent) of the Nickel-Based Superalloy CMSX-10K Heat Used in this Study

\begin{tabular}{lcccccccccc}
\hline Element & $\mathrm{Al}$ & $\mathrm{Ti}$ & $\mathrm{Cr}$ & $\mathrm{Co}$ & $\mathrm{Nb}$ & $\mathrm{Mo}$ & $\mathrm{Ta}$ & $\mathrm{W}$ & $\mathrm{Re}$ & $\mathrm{Ni}$ \\
\hline CMSX-10K & 5.8 & 0.2 & 2.3 & 3.3 & 0.1 & 0.4 & 8.3 & 5.5 & 6.3 & bal. \\
\hline
\end{tabular}

third-generation single-crystal nickel-based superalloy, alongside an SHT optimization exercise. The detailed analyses were conducted via microstructural characterization, thermo-physical analyses, and compositional measurements, where the dissolution of inter-dendritic areas and the evolution of the microstructure of the inter-dendritic regions as well as the changes in thermo-physical characteristics and compositional homogeneities were carefully examined as a function of SHT progression.

\section{EXPERIMENTAL}

\section{A. Material}

The material investigated in the current study is a typical third-generation single-crystal nickel-based superalloy, CMSX-10K (Cannon-Muskegon Corporation, Muskegon, MI), received in as-cast form. The composition of the CMSX-10K heat used in this study is shown in Table I.

Single crystal test bars of diameter $9 \mathrm{~mm}$ and length $80 \mathrm{~mm}$ were used in the study. These test bars were solidified on a cluster assembly with an imposed withdrawal rate of $1 \times 10^{-4} \mathrm{~m} \mathrm{~s}^{-1}$ and thermocouple measurements indicated an average thermal gradient of $3 \mathrm{~K} \mathrm{~mm}^{-1}$ at the solidification front. X-ray examination of the test bars indicated that the $\langle 001\rangle$ was within 5 to $10 \mathrm{deg}$ from the growth axis for all the bars utilized in this study. The primary dendrite arm spacing in the test bars was approximately 300 to $350 \mu \mathrm{m}$.

\section{B. Differential Scanning Calorimetry (DSC)}

The thermo-physical characteristics of the samples were determined using a Netzsch DSC 404 (Netzsch-Gerätebau GmbH, Selb, Germany). In this instrument, the sample holder has S-type thermocouples (Pt-Pt 10 pct $\mathrm{Rh}$ ) in both the sample and reference locations. The thermocouple in the sample location was calibrated against the melting temperatures of pure gold and pure nickel prior to the DSC measurements. Samples used for the DSC measurements were approximately $5 \mathrm{~mm}$ in diameter and $1.5 \mathrm{~mm}$ in height, produced via electro-discharge machining (EDM). The samples were manually ground with $\mathrm{SiC}$ grinding paper to remove EDM marks and finished to 2500-grit prior to the DSC measurements. Alumina crucibles were used in all DSC experiments. All DSC runs were performed in a dynamic high-purity argon environment with an argon flow rate of $50 \mathrm{~mL} \mathrm{~min}-1$. The heating rate was $20 \mathrm{~K}$ $\min ^{-1}$ from room temperature to $873 \mathrm{~K}\left(60{ }^{\circ} \mathrm{C}\right)$ and thereafter $10 \mathrm{~K} \mathrm{~min}^{-1}$ up to $1723 \mathrm{~K}\left(1450{ }^{\circ} \mathrm{C}\right)$, followed by a 15 -minute dwell at $1723 \mathrm{~K}\left(1450{ }^{\circ} \mathrm{C}\right)$ and then cooling at $10 \mathrm{~K} \mathrm{~min}^{-1}$ from $1723 \mathrm{~K}$ to $1273 \mathrm{~K}\left(1450{ }^{\circ} \mathrm{C}\right.$ to $1000{ }^{\circ} \mathrm{C}$ ). All DSC traces and thermo-physical data presented in this study were from the heating portion of the DSC experiments, which capture the thermal history associated with the material and prior processing determining the state of the material.

\section{Solution Heat Treatment (SHT)}

SHT trials were carried out in an AFT laboratory-scale vacuum furnace (Advanced Furnace Technology, Cambridge, U.K.). The furnace utilizes a graphite heating element and temperature control was achieved with a C-type thermocouple (W26 pct Re-W5 pct $\mathrm{Re}$ ) located near the heating element. The hot zone size was approximately $100 \mathrm{~mm}$ in diameter and $100 \mathrm{~mm}$ in height. The temperature in the center of the hot zone was calibrated against the melting points of pure gold and pure nickel prior to the SHT runs, and during the SHT runs the alloy samples were placed at this location. Within the hot zone, the temperature uniformity was within $\pm 1{ }^{\circ} \mathrm{C}$ as determined by scanning of the hot zone with a separate R-type thermocouple during the calibration process. As-cast CMSX-10K samples with dimensions of $9 \mathrm{~mm}$ diameter and $10 \mathrm{~mm}$ height were cut from as-cast bars for the SHT trials. After SHT runs in the vacuum furnace, the samples were subsequently prepared for microstructural characterization, DSC measurements, and compositional homogeneity measurements.

The aim of the SHT optimization exercise is to design an improved SHT cycle which dynamically tracks the progressive increase of the incipient melting temperature $\left(T_{\mathrm{IM}}\right)$ as the SHT progresses. The $T_{\mathrm{IM}}$ is the temperature at which localized incipient melting starts to occur within the microstructure; full details of the methodology adopted for the determination of the $T_{\mathrm{IM}}$ are presented in Section III-A. By tracking the increases in the $T_{\mathrm{IM}}$, the highest possible intermediate isothermal hold and peak SHT soak temperatures could be utilized to promote rapid homogenization of the compositional segregation but without causing incipient melting in the material. During ramp up and at isothermal hold, diffusion in the solid decreases the local elemental segregation, resulting in an increase in the $T_{\mathrm{IM}}$. Stepwise increments were added to the SHT cycle in light of the increase in $T_{\mathrm{IM}}$ after being subjected to earlier SHT steps. To prevent incipient melting within the sample, the temperature chosen for subsequent SHT steps was always lower than the $T_{\mathrm{IM}}$ associated with the prior SHT step, with addition of a conservative process safety margin of at least $5^{\circ} \mathrm{C}$.

Based on the DSC results of as-cast CMSX-10K, it was determined that the first intermediate isothermal hold step of the optimized SHT cycle could be implemented at $1627 \mathrm{~K}\left(1354{ }^{\circ} \mathrm{C}\right)$. The SHT ramp profile was 
Table II. An Optimized SHT Cycle Developed for CMSX-10K

\begin{tabular}{|c|c|c|c|}
\hline$T$ Start $\left[\mathrm{K}\left({ }^{\circ} \mathrm{C}\right)\right]$ & $T$ End $\left[\mathrm{K}\left({ }^{\circ} \mathrm{C}\right)\right]$ & Ramp Rate $\left({ }^{\circ} \mathrm{C} / \mathrm{min}\right)$ & Soak Time at $T$ End (min) \\
\hline $293(20)$ & $1473(1200)$ & 18.0 & 15 \\
\hline $1473(1200)$ & $1573(1300)$ & 5.0 & 15 \\
\hline $1573(1300)$ & $1618(1345)$ & 1.5 & 15 \\
\hline $1618(1345)$ & $1627(1354)$ & 0.15 & 60 \\
\hline $1627(1354)$ & $1635(1362)$ & 0.13 & 300 \\
\hline $1635(1362)$ & $1638(1365)$ & 0.05 & 1200 \\
\hline
\end{tabular}

devised to consist of progressively decreasing ramp rates when nearing the temperature of $1627 \mathrm{~K}\left(1354{ }^{\circ} \mathrm{C}\right)$ to prevent temperature overshoots in the furnace, which could potentially cause incipient melting within the sample. Subsequently, after being subjected to the 1627 $\mathrm{K}\left(1354{ }^{\circ} \mathrm{C}\right) / 15$ minute step, the $T_{\mathrm{IM}}$ had increased and the material was deemed suitable to be isothermally soaked at $1635 \mathrm{~K}\left(1362{ }^{\circ} \mathrm{C}\right)$. Therefore, after soak at $1627 \mathrm{~K}\left(1354{ }^{\circ} \mathrm{C}\right)$ for an arbitrarily chosen time of one hour to aid homogenization, additional SHT steps of $1635 \mathrm{~K}\left(1362{ }^{\circ} \mathrm{C}\right) / 15$ minute and $1635 \mathrm{~K}\left(1362{ }^{\circ} \mathrm{C}\right) / 5$ hour were added to assess the response of the material. The $1635 \mathrm{~K}\left(1362{ }^{\circ} \mathrm{C}\right) / 15$ minute step was used to ascertain the microstructure and $T_{\mathrm{IM}}$ at the end of the ramp-up of this step, while the $1635 \mathrm{~K}\left(1362^{\circ} \mathrm{C}\right) / 5$ hour step was devised to determine the microstructure and $T_{\mathrm{IM}}$ at the end of the isothermal hold step. Following the SHT steps up to $1635 \mathrm{~K}\left(1362{ }^{\circ} \mathrm{C}\right) / 5$ hour, the $T_{\mathrm{IM}}$ had again increased, and this allowed the material to be isothermally soaked at $1638 \mathrm{~K}\left(1365^{\circ} \mathrm{C}\right)$. The isothermal soak time at $1638 \mathrm{~K}\left(1365^{\circ} \mathrm{C}\right)$ was chosen to be 20 hours; the justification for this choice will be provided later in the discussion section. The complete SHT cycle devised in this study is presented in Table II. In the subsequent sections, the samples representative of the various stages of SHT are denoted according to the last SHT step which they had undergone in accordance to the SHT cycle shown in Table II, e.g., the $1635 \mathrm{~K}$ (1362 $\left.{ }^{\circ} \mathrm{C}\right) / 15$ minute sample was subjected to the $1635 \mathrm{~K}$ (1362 $\left.{ }^{\circ} \mathrm{C}\right)$ step with 15 minutes dwell, prior to which it had undergone the ramp up to $1627 \mathrm{~K}\left(1354^{\circ} \mathrm{C}\right)$, the soak at $1627 \mathrm{~K}\left(1354{ }^{\circ} \mathrm{C}\right)$ for 1 hour and the ramp from $1627 \mathrm{~K}$ $\left(1354{ }^{\circ} \mathrm{C}\right)$ to $1635 \mathrm{~K}\left(1362{ }^{\circ} \mathrm{C}\right)$.

At the end of the SHT runs, the samples were furnace-cooled in the vacuum furnace. Typical cooling rates were 15 to $20 \mathrm{~K} \mathrm{~min}^{-1}$ from the peak temperatures to approximately $1173 \mathrm{~K}\left(900{ }^{\circ} \mathrm{C}\right)$. These cooling rates are relatively slow to freeze the microstructure from the peak temperatures. However, the very slow processes associated with the changes in the compositional homogeneities and the microstructures of the inter-dendritic constituents during SHT, which are of primary interest in the current study, are not expected to be significantly altered by the slow furnace cooling.

\section{Microstructural Characterization and Composition Homogeneity Measurements}

Detailed examination of the microstructure of the inter-dendritic regions was carried out after the various SHT steps to study the microstructural evolution as a function of SHT progression. Samples for microstructural characterization were cut normal to the $\langle 001\rangle$ casting direction. Standard metallographic preparation techniques were used cumulating with a fine-polish using colloidal silica suspension. A Camscan MX2600 FEG-SEM (Tescan USA, Inc., Cranberry Township, PA) operating at an accelerating voltage of $20 \mathrm{kV}$ and a working distance of $10 \mathrm{~mm}$ was used in back-scattered electron imaging (BEI) mode for microstructural characterization.

Area fraction measurements of the inter-dendritic regions were carried out to quantify the dissolution of the inter-dendritic constituents during the progression of SHT. First, BEI images at low magnification to cover representative areas were obtained; typically 5 images were taken with each image covering an area of approximately $1.20 \mathrm{~mm} \times 0.96 \mathrm{~mm}$, typically encompassing 10 to 12 primary dendrites. Binary images were then produced manually from these BEI images and image analyses were subsequently carried out on these binary images with the ImageJ software (National Institutes of Health, MD, USA). The average, standard deviation as well as the maximum and minimum of the area fractions of the inter-dendritic regions were obtained.

Composition measurements were performed on flat as-polished samples using a Cameca SX100 (Cameca SAS, Gennevillier, France) equipped with an electron-probe micro-analyser (EPMA). Quantitative X-ray mapping was performed across an area of 1.25 $\mathrm{mm} \times 1.25 \mathrm{~mm}$ at $5 \mu \mathrm{m}$ intervals on the transverse section of the samples, generating a grid consisting of $251 \times 251$ data points. Each analysis area typically encompasses approximately 15 primary dendrites. The size of the analysis area was chosen to encompass as large an area as possible thereby obtaining data representative of typical compositional homogeneity in a given sample. The beam conditions were $20 \mathrm{kV}, 100 \mathrm{nA}$ and the beam was fully focused (excitation volume for most X-rays in the alloy was approximately 1 to 1.5 cubic microns). Typical $\gamma^{\prime}$ precipitate size in the material was approximately $400 \mathrm{~nm}$; therefore, the local composition comprising both the $\gamma$ and $\gamma^{\prime}$ phases was captured at each analysis spot. The following X-ray lines were used, the choice of lines being constrained by the need to avoid significantly overlapping lines: (i) $\mathrm{K} \alpha 1-\mathrm{Al}, \mathrm{Cr}$, Co, Ti, Ni; (ii) $\mathrm{L} \alpha 1-\mathrm{W}, \mathrm{Nb}, \mathrm{Mo}$; (iii) $\mathrm{M} \alpha 1-\mathrm{Ta}$, and (iv) $\mathrm{M} \beta 1-\mathrm{Re}$.

All calibration standards were pure (99.999 pct) metals except for $\mathrm{Al}$, for which pure synthetic corundum $\left(\mathrm{Al}_{2} \mathrm{O}_{3}\right)$ was used. The analyzing crystals used were 
Lithium Fluoride (LiF) for $\mathrm{Co}$ and $\mathrm{Ni}$; Large Lithium Fluoride ( $\mathrm{LLiF}$ ) for $\mathrm{Cr}$ and $\mathrm{W}$; Large Pentaerythritol (LPET) for $\mathrm{Ti}, \mathrm{Nb}, \mathrm{Mo}$, and Re; and Thallium Acid Phthalate (TAP) for Al and Ta. Background positions and slope factors were determined using the Virtual WDS software (Cambridge Enterprise Ltd., Cambridge, U.K.). ${ }^{[18]}$ Slope factors were calculated in place of measurement of background on the negative side of X-ray peaks for Mo and Ta, and on the positive side for $\mathrm{W}, \mathrm{Re}$, and $\mathrm{Nb}$. Both backgrounds were measured for all other elements. Pulse height analysis with spectrometers in differential mode was used to eliminate interfering signals for Mo and Ta.

\section{RESULTS}

\section{A. Thermo-physical Analysis}

The DSC results obtained from the material in the as-cast condition and after various SHT steps are shown in Figure 2(a). Note that the $y$-axis of Figure 2(a) is defined such that exothermic processes are plotted in the positive $y$-direction. In the as-cast condition, the initially horizontal line starts to show a gentle exothermic deviation over a large range of temperature, which is associated with the solid-state dissolution of the $\gamma^{\prime}$ precipitates, i.e., the $\gamma^{\prime}$ solvus. This is followed by two endothermic peaks, a first smaller peak at a particular temperature followed by a larger peak at a slightly higher temperature. The first small endothermic peak indicates the melting of the inter-dendritic constituents while the larger peak is associated with the melting of the bulk of the alloy, i.e., the primary $\gamma$ dendrites. After being subjected to various SHT, the initially gentle $\gamma^{\prime}$ solvus becomes more distinct and occurs over a smaller temperature range compared to the as-cast condition. The range of temperature over which $\gamma^{\prime}$ solvus occurs also appear to be progressively increased with increasing SHT steps. After the final $1638 \mathrm{~K}\left(1365{ }^{\circ} \mathrm{C}\right) / 20$ hour step, the $\gamma^{\prime}$ solvus was noted to occur between approximately $1618 \mathrm{~K}$ and $1628 \mathrm{~K}\left(1345^{\circ} \mathrm{C}\right.$ and $\left.1355^{\circ} \mathrm{C}\right)$. The

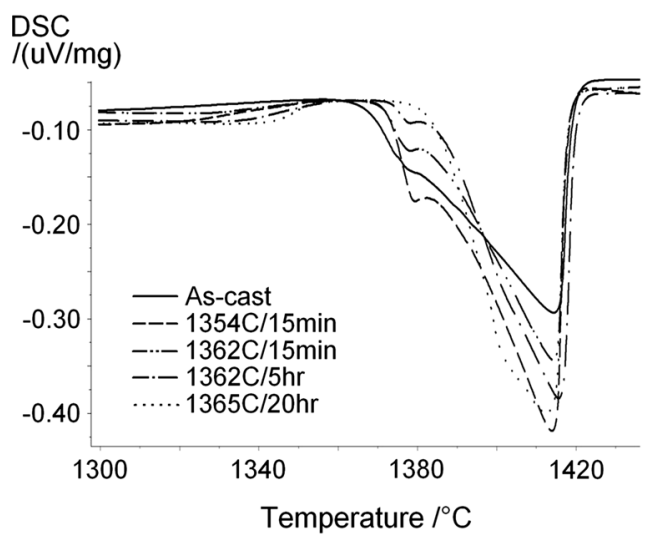

(a) minor peak also noticeably diminishes in size with increasing SHT steps compared to the as-cast condition, eventually disappearing altogether after the final $1638 \mathrm{~K}$ $\left(1365^{\circ} \mathrm{C}\right) / 20$ hour step.

The incipient melting temperature, $T_{\mathrm{IM}}$, is defined as the temperature at which localized incipient melting start to occur within the microstructure. In order to determine $T_{\text {IM }}$ accurately, the first derivative of the raw DSC signal was examined. Note that since similar heating rates were used in all DSC measurements, the time-derivative $d(\mathrm{DSC}) / d t$ as shown in Figure 2(b) is proportional to the temperature-derivative $d(\mathrm{DSC}) / d T$. The $T_{\mathrm{IM}}$ corresponds to the temperature at which the raw DSC signal (heating portion) first exhibits an endothermic deviation from the tangent to the bulk solid line near the onset of the minor peak, i.e., the temperature at which $d(\mathrm{DSC}) / d t$ crosses below -0.01 . This temperature is associated with a much more pronounced change in the slope of the raw DSC signal (compared to the relatively subtle change in the slope of the raw DSC signal when $d(\mathrm{DSC}) / d t$ crosses below zero). This approach enables the $T_{\mathrm{IM}}$ to be determined accurately.

The raw DSC signal is assumed to be proportional to the specific heat capacity difference between the sample and reference, which has been pointed out by Boettinger et al. ${ }^{[19]}$ to be only true when no latent heat evolves in the sample during melting and solidification. However, latent heat always evolves in the sample during melting and solidification, as such the raw DSC signal is smeared over a range of temperatures. In the determination of $T_{\mathrm{IM}}$ that is associated with the very first solid to undergo melting, the effects of latent heat evolution on the DSC signal are expected to be minimal; therefore, the $T_{\mathrm{IM}}$ determined from the raw DSC signals in this study are expected to be reasonably accurate.

The $T_{\mathrm{IM}}$ for the as-cast condition and after the various SHT steps are summarized in Table III. The minor peak associated with the inter-dendritic areas shifts rapidly during the early stages of the SHT ramp and hold steps, resulting in a significantly reduced

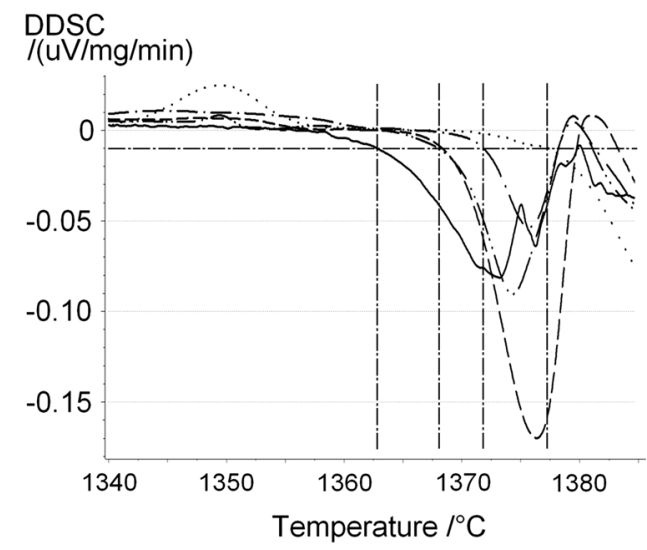

(b)

Fig. 2-(a) Raw DSC heating curves for the as-cast condition and after various SHT steps, and (b) d(DSC)/d $t$ of the raw DSC heating curves for the as-cast condition and after various SHT steps. The deviations from the horizontal baseline in (b) show the onset of incipient melting; the vertical lines indicate the $T_{\mathrm{IM}}$ determined for the as-cast condition and after various SHT steps, according to the method described in the text. The $T_{\mathrm{IM}}$ was seen to progressively increase as SHT progresses. 
Table III. Incipient Melting Temperatures $T_{\mathrm{IM}}$ for the As-Cast Condition and After Various SHT Steps

\begin{tabular}{lc}
\hline Material/SHT Condition & $T_{\mathrm{IM}}\left[\mathrm{K}\left({ }^{\circ} \mathrm{C}\right)\right]$ \\
\hline As-cast & $1635(1362)$ \\
$1627 \mathrm{~K}\left(1354^{\circ} \mathrm{C}\right) / 15 \mathrm{~min}$ & $1641(1368)$ \\
$1635 \mathrm{~K}\left(1362^{\circ} \mathrm{C}\right) / 15 \mathrm{~min}$ & $1641(1368)$ \\
$1635 \mathrm{~K}\left(1362^{\circ} \mathrm{C}\right) / 5 \mathrm{~h}$ & $1645(1372)$ \\
$1638 \mathrm{~K}\left(1365^{\circ} \mathrm{C}\right) / 20 \mathrm{~h}$ & $1651(1378)$ \\
\hline
\end{tabular}

magnitude of the minor peak and large shifts toward higher $T_{\mathrm{IM}}$. The $T_{\mathrm{IM}}$ was promptly raised from $1635 \mathrm{~K}$ $\left(1362{ }^{\circ} \mathrm{C}\right)$ for the as-cast condition to $1641 \mathrm{~K}\left(1368{ }^{\circ} \mathrm{C}\right)$ after the $1627 \mathrm{~K}\left(1354{ }^{\circ} \mathrm{C}\right) / 15$ minute step. Subsequently, even after a reasonable soak at elevated temperatures during the intermediate stages of the SHT cycle up to the $1635 \mathrm{~K}\left(1362{ }^{\circ} \mathrm{C}\right) / 15$ minute step, the minor peak still persisted, albeit decreased in magnitude. There was no change in the $T_{\mathrm{IM}}[=1641 \mathrm{~K}$ $\left.\left(1368{ }^{\circ} \mathrm{C}\right)\right]$ after the $1635 \mathrm{~K}\left(1362{ }^{\circ} \mathrm{C}\right) / 15$ minute step compared to the $1627 \mathrm{~K}\left(1354{ }^{\circ} \mathrm{C}\right) / 15$ minute step. Following prolonged soak in the $1635 \mathrm{~K}\left(1362{ }^{\circ} \mathrm{C}\right) / 5$ hour step, i.e., an additional $43 / 4$ hours hold at $1635 \mathrm{~K}$ $\left(1362{ }^{\circ} \mathrm{C}\right)$ compared to the $1635 \mathrm{~K}\left(1362{ }^{\circ} \mathrm{C}\right) / 15$ minute step, the minor peak diminished further, resulting in a concomitant increase in the $T_{\mathrm{IM}}$ to $1645 \mathrm{~K}\left(1372{ }^{\circ} \mathrm{C}\right)$. After the final soak of $1638 \mathrm{~K}\left(1365{ }^{\circ} \mathrm{C}\right) / 20$ hour, the minor peak disappeared altogether indicating the complete or near-complete dissolution of all the inter-dendritic areas; the $T_{\mathrm{IM}}$ at this stage was raised significantly to $1651 \mathrm{~K}\left(1378^{\circ} \mathrm{C}\right)$ which approached the commencement of the melting of the primary $\gamma$ dendrite i.e., the solidus temperature of the material.

\section{B. Evolution of Microstructure During SHT}

Low-magnification BEI images of the microstructures in the as-cast condition and after various SHT steps are shown in Figure 3. The inter-dendritic areas which are mostly inter-connected and continuous along the dendrite lobe periphery in the as-cast condition become increasingly fragmented and are clearly observed to diminish in area fraction with increasing SHT steps. However, despite the near-complete dissolution of the inter-dendritic constituents after the final $1638 \mathrm{~K}$ (1365 $\left.{ }^{\circ} \mathrm{C}\right) / 20$ hour step, compositional gradients can still be observed across the microstructure, as shown by atomic contrasts of the BEI micrograph in Figure 3(e).

The area fractions of the inter-dendritic constituents in the as-cast condition and after various SHT steps are summarized in Table IV. There was a large scatter in the area fraction measurements as shown by the standard deviations for the as-cast condition as well as the early stages of SHT. This was due to the distribution of the inter-dendritic regions being highly irregular and therefore depended significantly on the measurement area chosen. From Table IV, a clear trend of decreasing inter-dendritic area fraction with the progression of the SHT was observed, in agreement with the overviews of the microstructures as shown in Figure 3. It is worth noting that the maximum (pct) inter-dendritic area fraction for a given SHT step was always lower than the minimum (pct) of the preceding step. This is unequivocal evidence that significant dissolution of the inter-dendritic constituents had occurred in that given SHT step. The scatter (standard deviations) associated with the area fraction measurements also decreased with the progression of SHT, indicating improving microstructural uniformity as the irregular inter-dendritic areas were progressively dissolved. The inter-dendritic area fraction was near-zero after the final $1638 \mathrm{~K}$ $\left(1365{ }^{\circ} \mathrm{C}\right) / 20$ hour step, where almost all the remnant inter-dendritic areas were dissolved.

The evolution of the microstructure of the inter-dendritic regions after various SHT steps is shown in greater detail in Figures 4 through 7. Bearing in mind the microstructure of the inter-dendritic regions in the as-cast condition as detailed in the introduction (Figure 1), the microstructural evolution associated with the fine $\gamma / \gamma^{\prime}$ morphology and that of the coarse cellular $\gamma^{\prime} /$ narrow $\gamma$ channel morphology during the progression of the SHT are examined in turn.

First, examining the evolution of the fine $\gamma / \gamma^{\prime}$ morphology, after the ramp to $1627 \mathrm{~K}\left(1354 \mathrm{C}^{\circ}\right) / 15$ minute, the fine $\gamma / \gamma^{\prime}$ morphology was noted to undergo rapid coarsening, which was observed when comparing Figure 4(d) with that of the as-cast condition shown in Figures 1(b) and (c). The lamellar nature was retained; however, a coarser inter-lamellar spacing was apparent. The coarsening of the fine $\gamma / \gamma^{\prime}$ morphology continued as the SHT progresses; however, the rate of coarsening appeared diminished as the $\gamma / \gamma^{\prime}$ spacing only increased marginally from one SHT step to the next. This can be observed when comparing Figures 4(c) with 5(c), (d) and 6(c). The coarsened $\gamma / \gamma^{\prime}$ morphology evolution continued with the sluggish dissolution of the $\gamma$ lamellae while the $\gamma^{\prime}$ phase persisted for much longer periods. The coarsened $\gamma / \gamma^{\prime}$ morphology in which the $\gamma$ lamellae had further dissolved was observed as isolated islands of predominantly $\gamma^{\prime}$ phase with embedded sporadic $\gamma$ channels/debris, as shown in Figures 6(d) and 7(a). As a note of caution, it is worth pointing out that this appearance is very similar to and may be mistaken for the coarse cellular $\gamma^{\prime}$ /narrow $\gamma$ channel morphology observed in the as-cast condition. However, the areas of the coarsened $\gamma / \gamma^{\prime}$ morphology are usually observed remote from pores [highlighted in Figure 6(b)] while the coarse cellular $\gamma^{\prime}$ structures in the as-cast condition, which were the last regions to solidify, are usually located adjacent to pores. This key aspect should be used to delineate the two morphologies. After the final soak at $1638 \mathrm{~K}\left(1365{ }^{\circ} \mathrm{C}\right) / 20$ hour, sporadic inter-dendritic areas associated with the coarsened $\gamma / \gamma^{\prime}$ morphology could still be observed as shown in Figure 7.

Moving on to examine the evolution of the coarse cellular $\gamma^{\prime}$ /narrow $\gamma$ channel morphology, a progressive disappearance of the coarse cellular $\gamma^{\prime}$ structures was observed as SHT progresses. In areas where remnant cellular $\gamma^{\prime}$ structures were still observed, the narrow $\gamma$ channels separating the cellular $\gamma^{\prime}$ structures were seen to dissolve within the coarse $\gamma^{\prime}$ structure, leading to the globular appearance of the coarse $\gamma^{\prime}$ structures, as shown at the top right area in Figure 5(b). This is 

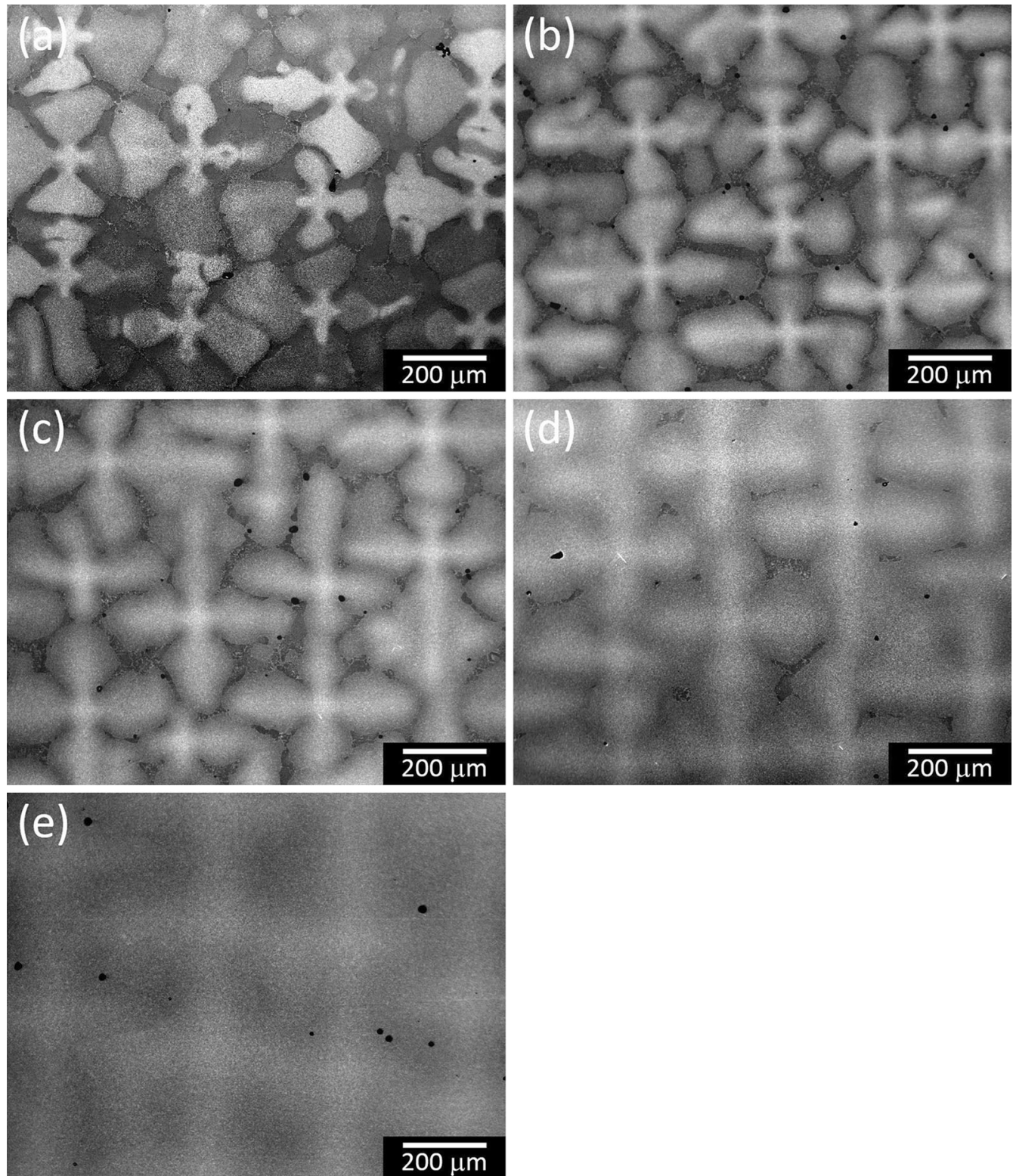

Fig. 3-Back-scattered imaging (BEI) overview of the CMSX-10K microstructure $(a)$ as-cast condition and after various SHT steps $(b) 1627 \mathrm{~K}$ $\left(1354{ }^{\circ} \mathrm{C}\right) / 15 \mathrm{~min},(c) 1635 \mathrm{~K}\left(1362^{\circ} \mathrm{C}\right) / 15 \mathrm{~min},(d) 1635 \mathrm{~K}\left(1362^{\circ} \mathrm{C}\right) / 5 \mathrm{~h}$, and $(e) 1638 \mathrm{~K}\left(1365^{\circ} \mathrm{C}\right) / 20 \mathrm{~h}$.

Table IV. Inter-dendritic Area Fraction Measurements for the As-Cast Condition and After Various SHT Steps

\begin{tabular}{|c|c|c|c|c|}
\hline Material/SHT Condition & Mean (pct) & $\mathrm{SD}(\mathrm{pct})$ & $\operatorname{Min}(p c t)$ & $\operatorname{Max}(p c t)$ \\
\hline As-cast & 21.7 & \pm 2.1 & 18.5 & 23.6 \\
\hline $1627 \mathrm{~K}\left(1354{ }^{\circ} \mathrm{C}\right) / 15 \mathrm{~min}$ & 15.6 & \pm 1.3 & 13.6 & 17.1 \\
\hline $1635 \mathrm{~K}\left(1362{ }^{\circ} \mathrm{C}\right) / 15 \mathrm{~min}$ & 10.2 & \pm 1.2 & 8.6 & 11.6 \\
\hline $1635 \mathrm{~K}\left(1362^{\circ} \mathrm{C}\right) / 5 \mathrm{~h}$ & 3.4 & \pm 0.9 & 2.1 & 4.4 \\
\hline $1638 \mathrm{~K}\left(1365^{\circ} \mathrm{C}\right) / 20 \mathrm{~h}$ & 0.02 & \pm 0.02 & 0.00 & 0.05 \\
\hline
\end{tabular}

markedly different and may appear to have larger globular size compared with the coarse cellular $\gamma^{\prime}$ structures of the as-cast condition as shown in Figure 1(d).

The dissolution of inter-dendritic areas with both morphologies was accomplished by inward growth of the $\gamma$ dendrites into the inter-dendritic areas.
Inter-dendritic areas with the coarse cellular $\gamma^{\prime}$ structures were observed to dissolve more readily compared to the coarsened $\gamma / \gamma^{\prime}$ areas (originating from the fine $\gamma / \gamma^{\prime}$ morphology in the as-cast condition), which persisted to the intermediate and late stages of SHT. Initial inward growth of $\gamma$ dendrites occurred at the majority of the coarse cellular $\gamma^{\prime}$ areas, in some cases this was 

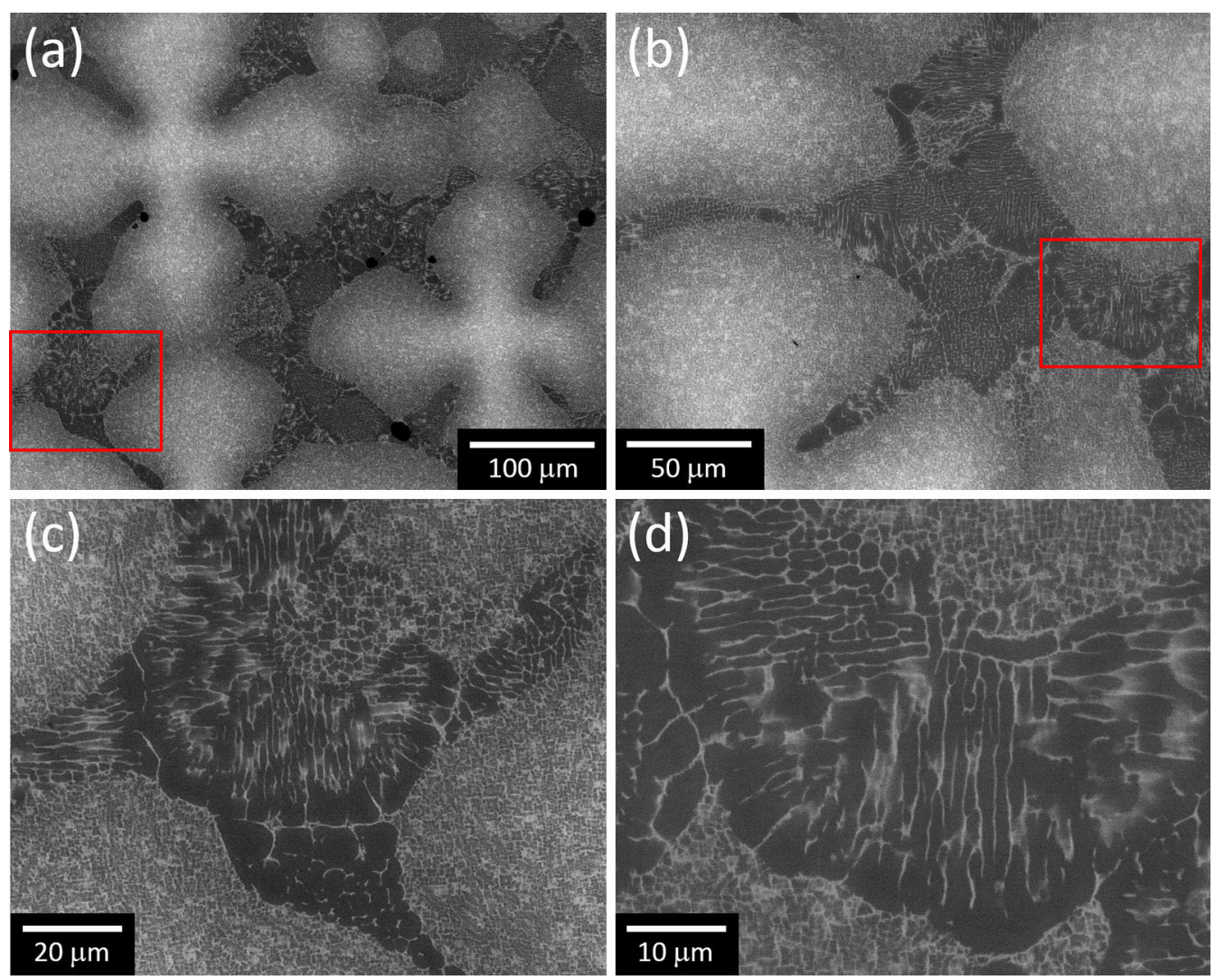

Fig. 4-Microstructure of inter-dendritic regions after $1627 \mathrm{~K}\left(1354{ }^{\circ} \mathrm{C}\right) / 15 \mathrm{~min}$ step (BEI) $(a)$ and $(b)$; $(c)$ and $(d)$ high magnification of areas highlighted in (a) and (b), respectively.

highlighted by the location of pores. In the as-cast condition, pores are usually located adjacent to the coarse cellular $\gamma^{\prime}$ structures which are the last areas to solidify. After being subjected to the SHT steps, some pores became totally enveloped within the dendrite, e.g., in Figures 5(a) and 6(b), indicating the movement of the dendrite lobe periphery into what were originally coarse cellular $\gamma^{\prime}$ inter-dendritic areas in the as-cast condition.

\section{Evolution of Compositional Homogeneity}

There were uncertainties associated with the compositional data due to the rapid acquisition rate of the quantitative data via mapping (compared to slower grid analyses where the electron beam dwells at a particular spot for much longer periods). The distributions of the wt pct sum of all the elements analyzed at each data point for a particular data set of a given sample in the as-cast condition and after various SHT steps are shown in Figure 8. The average of the wt pct sum of all the elements analyzed at each data point was approximately 101 pct within the data set of a given sample, with a standard deviation of up to 5.6 pct. However, the shape of the histograms associated with the wt pct sum of the elements analyzed (and the associated standard deviations) were relatively similar for the data sets of various samples. The uncertainties therefore appear to be consistent across all the data sets. The quantitative data of the elements analyzed at each data point were subsequently normalized (to attain $100 \mathrm{wt}$ pct total at the particular data point) for all the data sets, after which the relevant data associated with each sample were used to compare the compositional homogeneities in the as-cast condition as well as that attained after various SHT steps.

Data are only shown for $\mathrm{Al}, \mathrm{Cr}, \mathrm{Ta}, \mathrm{W}$, and $\mathrm{Re}$, which are more strongly segregating and among the slowest diffusing. These data provide the most sensitive indication of the extent of compositional homogeneities after the various SHT steps. Quantitative EPMA X-ray maps of the samples in the as-cast condition and after various SHT steps are shown in Figure 9, where the decrease in the inter-dendritic area fraction with the progression of SHT could be observed more clearly. The trend of decreasing inter-dendritic area fraction in Figure 9 is consistent with that of Figure 3 and the data presented in Table IV. In the as-cast condition, strong segregation of $\mathrm{W}$ and Re to dendritic areas, and conversely Al and Ta to the inter-dendritic regions is shown by the strong contrast across the dendritic and inter-dendritic areas in the maps in Figure 9(a). In the as-cast condition, $\mathrm{Cr}$ shows a very distinct segregation behavior, which has also been reported in other single-crystal nickel-based superalloys. ${ }^{[20]}$ Relatively high concentrations of $\mathrm{Cr}$ were observed in the dendrite areas, which then decrease to much lower levels in subsequent inter-dendritic areas to form. However, there is a significant peak in the $\mathrm{Cr}$ concentrations at one edge of the inter-dendritic areas 

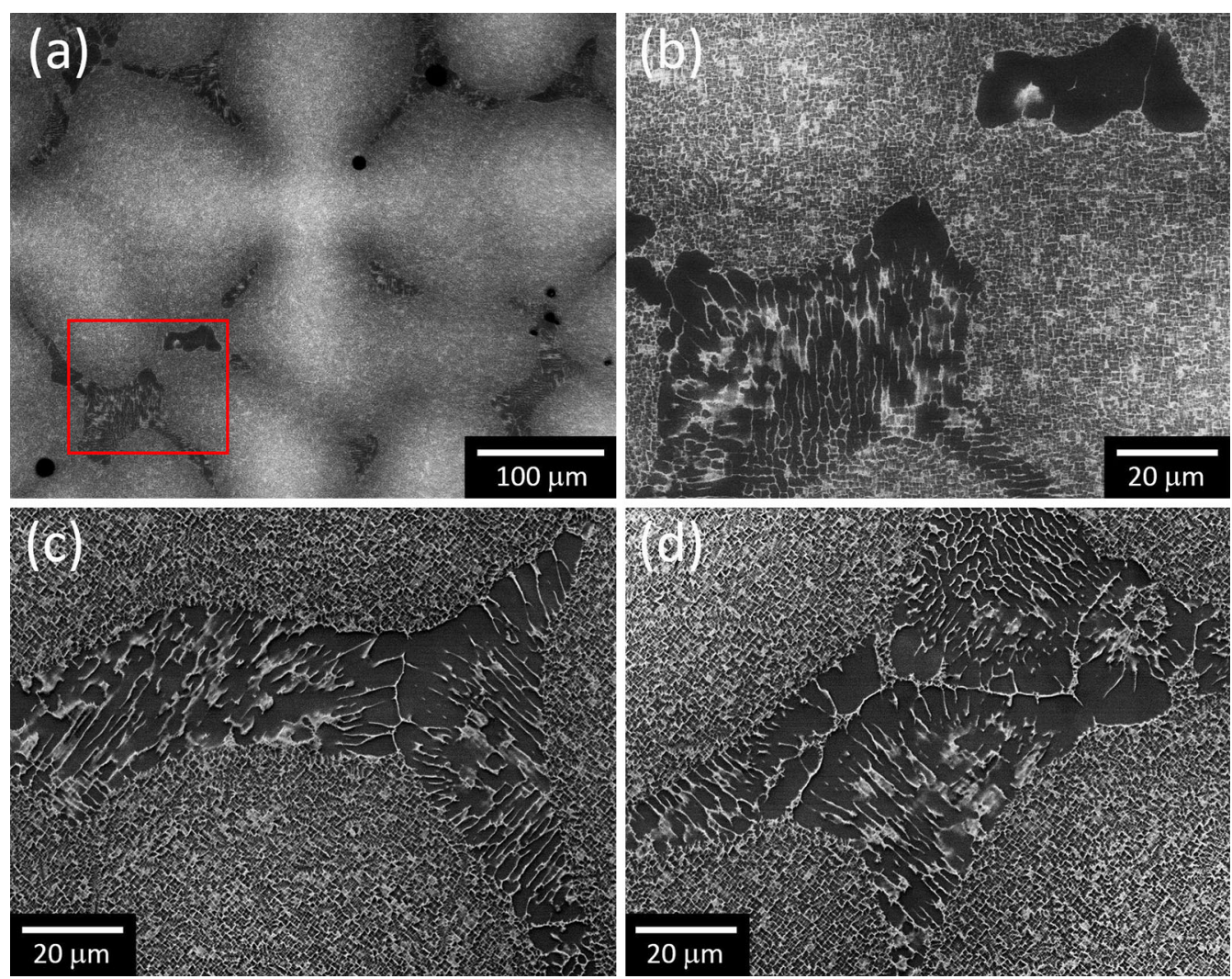

Fig. 5-Microstructure of inter-dendritic regions after $1635 \mathrm{~K}\left(1362{ }^{\circ} \mathrm{C}\right) / 15 \mathrm{~min}$ step (BEI) $(a)$; $(b)$ high magnification of highlighted area in (a); $(c)$ and $(d)$ other examples of inter-dendritic areas in after the $1635 \mathrm{~K}\left(1362{ }^{\circ} \mathrm{C}\right) / 15 \mathrm{~min}$ SHT step.

adjacent to the dendrites; the concentration of $\mathrm{Cr}$ in these areas which were the last areas to solidify is in general even higher than that of the dendrite areas.

With the progression of SHT, the strong segregation of elements across the dendritic and inter-dendritic areas of the material in the as-cast condition diminished and became progressively weaker, accompanied by the continuous dissolution of the inter-dendritic areas. The high concentrations of $\mathrm{Cr}$ seen at the edge of the inter-dendritic areas in the as-cast condition also diminished very quickly, and were no longer observed even after the first $1627 \mathrm{~K}\left(1354^{\circ} \mathrm{C}\right) / 15$ minute step. After the final soak at $1638 \mathrm{~K}\left(1365^{\circ} \mathrm{C}\right) / 20$ hour where almost all the inter-dendritic areas have dissolved, residual micro-segregation of the elements across the microstructure persisted and could not be completely eliminated. This residual micro-segregation is apparent and could be observed distinctly in Figure 9(e), which mirrors the observation in Figure 3(e).

In order to show the degree of compositional segregation in the as-cast condition and after the various SHT steps more unambiguously, the wt pct distributions of each element for the various material conditions were further analyzed from the quantitative data shown in Figure 9. The histograms of the normalized wt pct distribution associated with the various material conditions are shown in Figure 10 for each of the elements Al, $\mathrm{Cr}, \mathrm{Ta}, \mathrm{W}$, and $\mathrm{Re}$. The $x$-axes in these plots indicate corresponding element content in wt pct while the $y$-axes indicate the number of data points (denoted by normalized frequency) associated with the wt pct bin intervals within the data set. The dashed vertical lines represent the averages of the maximum peak positions (mode of the wt pct distribution), i.e., the average wt pct content of the particular element in the samples while the solid vertical lines denote the nominal wt pet content of the particular element in the alloy as shown in Table I. In most cases the dashed vertical lines were very close to the solid vertical lines (within $0.25 \mathrm{wt}$ pct), i.e., the wt pct content of the element in the sample was close to or equivalent to the nominal wt pct content, the only exception was for the element Al where there was a much larger discrepancy of approximately $0.4 \mathrm{wt}$ pct between the Al content in the sample and the nominal $\mathrm{Al}$ content. This may be due to uncertainties associated with the rapid EPMA measurement method or due to small deviations in the actual composition of the as-received material compared to the nominal composition; irrespective this discrepancy was consistent across all the data sets, and therefore the data could still be rightly used to compare the compositional homogeneities of the various material conditions. In addition, the averages and standard deviations associated with the normalized quantitative data shown in the histograms in Figure 10 were also computed; the results are shown in Table V for the as-cast condition and after various SHT steps.

In the as-cast condition, a large spread in the wt pct distribution of the elements was observed in Figure 10, which was particularly pronounced for $\mathrm{Ta}, \mathrm{W}$ and $\mathrm{Re}$. 

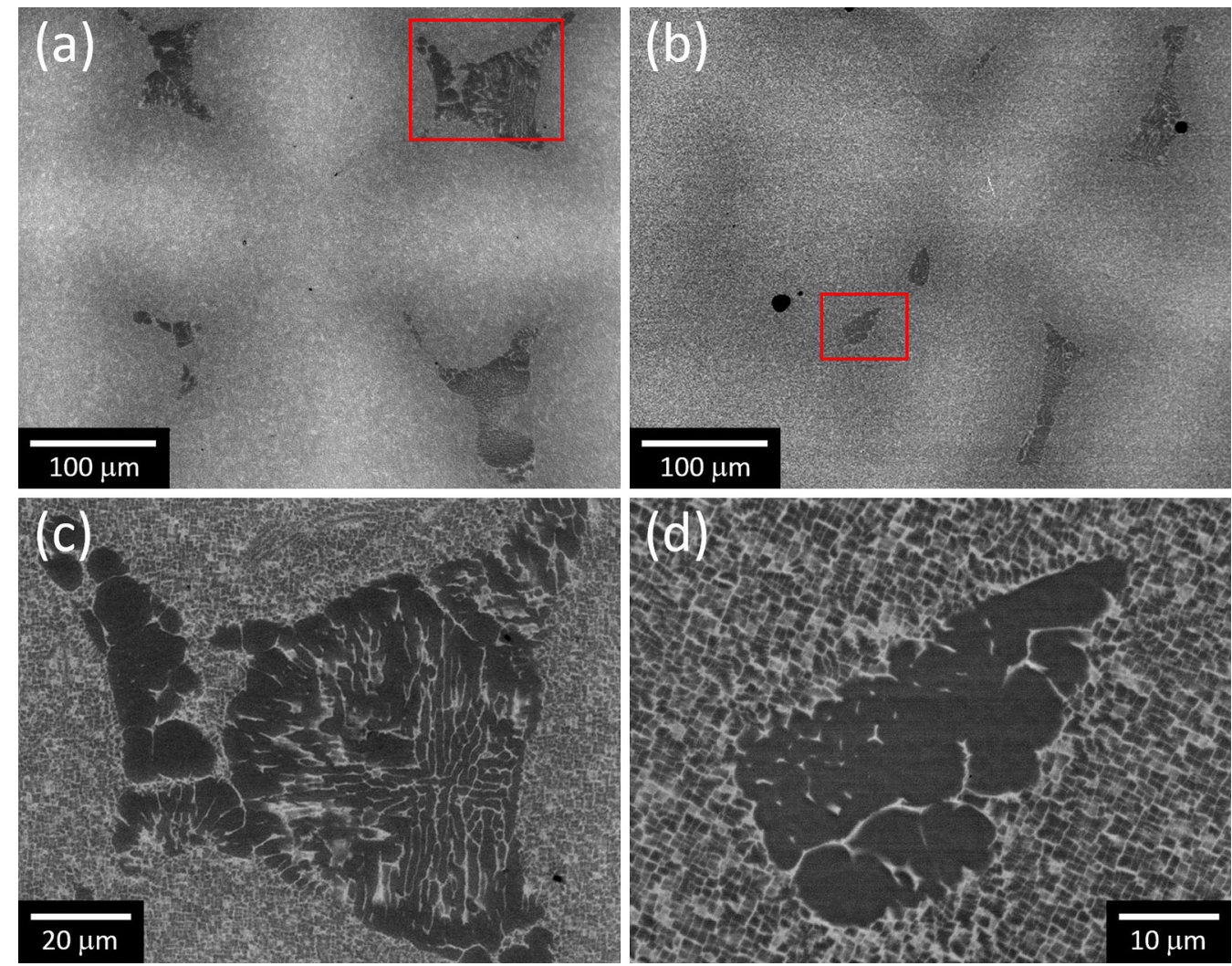

Fig. 6 - Microstructure of inter-dendritic regions after $1635 \mathrm{~K}\left(1362{ }^{\circ} \mathrm{C}\right) / 5 \mathrm{~h}$ step (BEI) $(a)$ and $(b) ;(c)$ and $(d)$ high magnification of areas highlighted in (a) and (b), respectively.
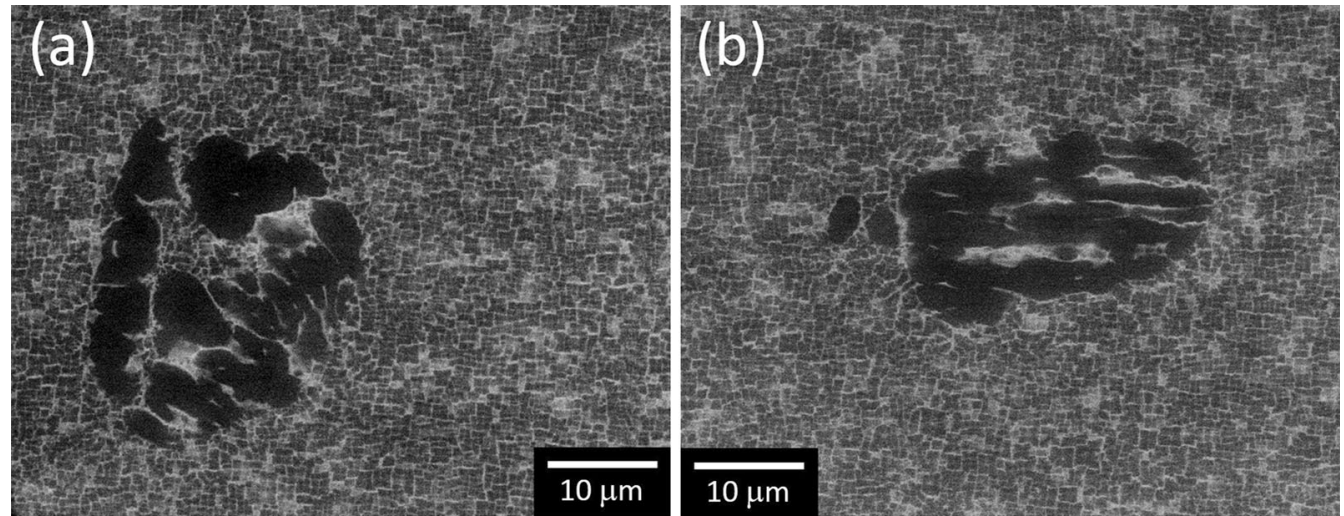

Fig. 7-Microstructure of inter-dendritic regions after $1638 \mathrm{~K}\left(1365^{\circ} \mathrm{C}\right) / 20 \mathrm{~h}(\mathrm{BEI})$.

This trend is also shown quantitatively by the standard deviations of these elements for the as-cast condition in Table V. With the progression of SHT, the peaks of the wt pet distribution of the elements became sharper and more distinct, i.e., wt pct distribution of the elements became progressively narrower and the magnitude of the peaks increased concomitantly. An increasing number of points were therefore attaining compositions closer to the nominal sample composition, implying that the composition homogeneity was increasing with the progression of SHT. This was also indicated by the decreasing standard deviations for the various elements as the SHT progresses in Table V. The residual micro-segregation after the final soak at $1638 \mathrm{~K}$ $\left(1365^{\circ} \mathrm{C}\right) / 20$ hour observed in Figure 9(e) was quantitatively reflected in the relatively large spread in the wt pct distribution of each element about the nominal sample composition shown in the histograms in Figure 10, with corresponding standard deviations of the wt pet distribution shown in Table V.

There was an unexpected behavior in the quantitative data of $\mathrm{Cr}$, as shown by the $\mathrm{Cr}$ wt pet distribution in Figure 10. Compared to the as-cast condition, the wt pet distribution of $\mathrm{Cr}$ associated with the $1627 \mathrm{~K}\left(1354{ }^{\circ} \mathrm{C}\right) /$ 15 minute showed a peak position at slightly higher wt pet $\mathrm{Cr}$, in addition there was a much higher number of 


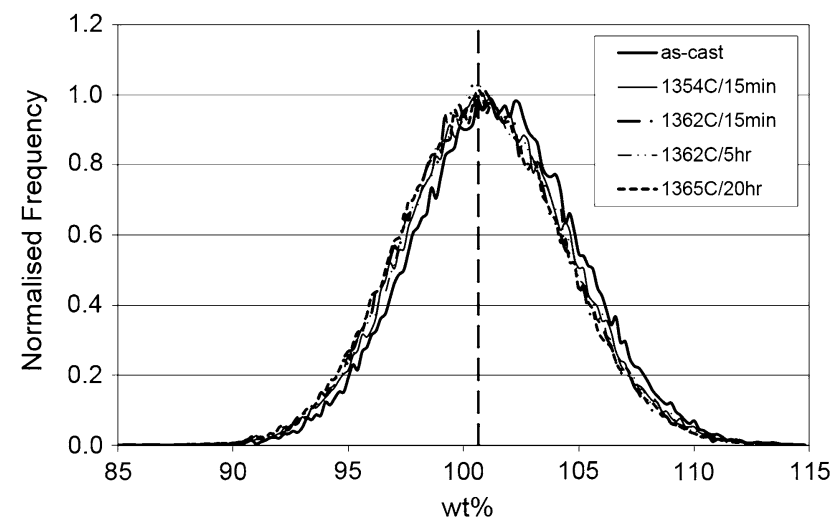

Fig. 8-The distribution of the wt pct sum of all elements at each data point in the data sets of the as-cast condition and after various SHT steps obtained with EPMA X-ray mapping. The dashed vertical line indicates the mean of the distribution of the wt pet sum of all elements at each data point for the various data sets.

data points with very low concentrations of up to $2 \mathrm{wt}$ pct Cr. With successive SHT steps, the peak positions shifted progressively to lower wt pet $\mathrm{Cr}$ accompanied by an increase in the peak height. The low wt pet $\mathrm{Cr}$ data reduced in proportion up to the $1638 \mathrm{~K}\left(1365{ }^{\circ} \mathrm{C}\right) / 20$ hour step at which most of these low wt pct data points were eliminated. The difference in the wt pet distribution between the as-cast condition and the $1627 \mathrm{~K}\left(1354{ }^{\circ} \mathrm{C}\right) /$ 15 minutes step was not related to the peak in $\mathrm{Cr}$ concentrations at one edge of the inter-dendritic regions described earlier; rather this difference appeared to suggest that during early SHT, the $\mathrm{Cr}$ concentrations of the inter-dendritic areas are further decreased from the already low concentrations, as shown by the increase in the quantity of data with very low wt pet of up to $2 \mathrm{wt}$ pct $\mathrm{Cr}$, while the concentrations of $\mathrm{Cr}$ in the dendrite areas were further increased, indicated by the shift in the peak height to higher wt pet $\mathrm{Cr}$. This increase is likely to be driven by the homogenization of the $\mathrm{Cr}$ enrichment at the edges of the inter-dendritic regions in addition to the movement of $\mathrm{Cr}$ from inter-dendritic areas, which further decreased in $\mathrm{Cr}$ concentrations. This behavior is rather counter-intuitive, i.e., it suggests that $\mathrm{Cr}$ was further rejected from the inter-dendritic areas, which already had low $\mathrm{Cr}$ concentrations and transported to the dendrite areas against the composition gradients. As such, it appears that homogenization of $\mathrm{Cr}$ across the dendrite and inter-dendritic areas may not be able to occur independently, rather $\mathrm{Cr}$ homogenization may only occur relatively locally within the dendrite areas and global $\mathrm{Cr}$ homogenization must be complemented by growth of the dendrite areas with corresponding dissolution of the inter-dendritic areas to homogenize the areas with low $\mathrm{Cr}$ concentrations.

The histograms in Figure 10 and the data in Table V also provide additional detail regarding the evolution of compositional homogeneity as the SHT progresses. In the early stage of SHT, a very large and rapid change in the shape of the wt pct distribution of the elements was observed going from the as-cast condition to the $1627 \mathrm{~K}$ (1354 $\left.{ }^{\circ} \mathrm{C}\right) / 15$ minute step. The wt pet distribution narrowed very pronouncedly and the peak height increased distinctly for most elements shown. With further progression of SHT, the peaks of the wt pct distributions do progressively become narrower and higher in magnitude, however the pace of the change was significantly slower and less marked from one SHT step to the next even up the final SHT step. These changes were also apparent when comparing the standard deviation data in Table V; large decreases in the standard deviations were observed going from the as-cast condition to the $1627 \mathrm{~K}\left(1354{ }^{\circ} \mathrm{C}\right) / 15$ minute step. With subsequent SHT steps, the decreases in the standard deviations of individual elements were more gradual from one SHT step to the next.

\section{DISCUSSION}

\section{A. Thermo-physical Characteristics}

The gentle exothermic deviation observed on the DSC trace of the as-cast material, Figure 2(a), is associated with the solid-state dissolution of $\gamma^{\prime}$ precipitates which occurs over a large range of temperature. This is associated with the large spread in the composition of the $\gamma$ dendrites, and in turn, the compositions of the $\gamma^{\prime}$ precipitates precipitated in the solid-state on cooling, arising as a consequence of the preferential partitioning of the alloying elements to the solid or liquid during solidification.

The progressive reduction in the magnitude of the minor peak with increasing SHT steps shows qualitatively the continuous dissolution of the inter-dendritic constituents as SHT progresses; the minor peak eventually disappears completely after the final soak at 1638 $\mathrm{K}\left(1365{ }^{\circ} \mathrm{C}\right) / 20$ hour when the inter-dendritic constituents were almost completely dissolved (near-zero levels). Therefore, the minor peak is categorically associated with the inter-dendritic constituents. Thermodynamic calculations using the Thermo-calc thermodynamic software ${ }^{[21]}$ indicate that under equilibrium conditions at the temperature of the final soak of $1638 \mathrm{~K}$ $\left(1365{ }^{\circ} \mathrm{C}\right)$, the CMSX-10K alloy comprises only the $\gamma$ phase, i.e., for the fully homogenized microstructure, the inter-dendritic constituents are completely dissolved and the minor peak eliminated. This was essentially achieved after the final soak at $1638 \mathrm{~K}\left(1365^{\circ} \mathrm{C}\right) / 20$ hour, with the exception of the sporadic undissolved inter-dendritic areas and the residual elemental micro-segregation observed.

\section{B. Evolution of $T_{I M}$, Composition and Microstructure of Inter-dendritic Areas}

A clearer correlation between the dissolution of the inter-dendritic areas, the changes in thermo-physical characteristics, and the evolution of compositional homogeneity as a function of SHT progression is shown in Figure 11. The $x$-axes of these plots denotes the time above $1618 \mathrm{~K}\left(1345^{\circ} \mathrm{C}\right)$ during the SHT, chosen in a simplistic approach to represent the progression of SHT. The temperature of $1618 \mathrm{~K}\left(1345^{\circ} \mathrm{C}\right)$ is the $\gamma^{\prime}$ solvus start temperature after the full SHT cycle, as obtained 


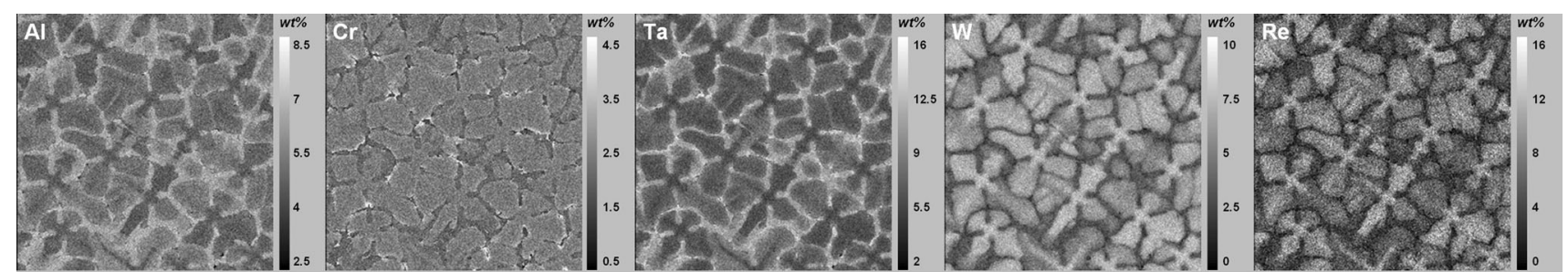

(a)

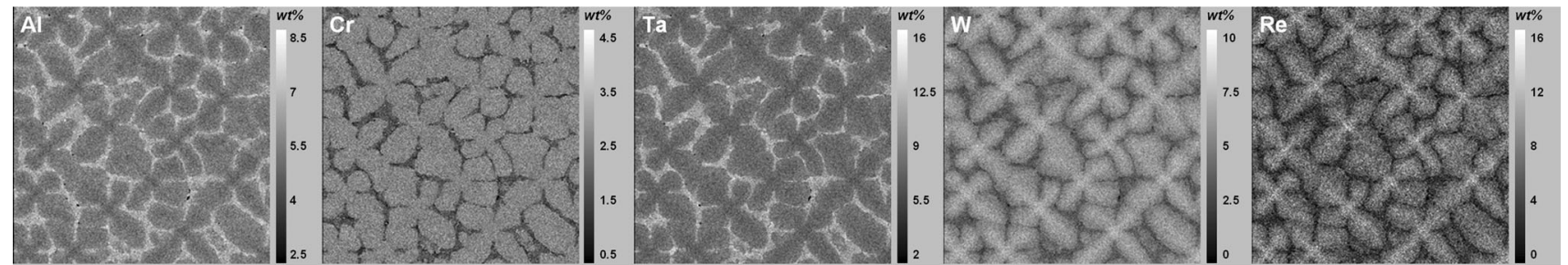

(b)

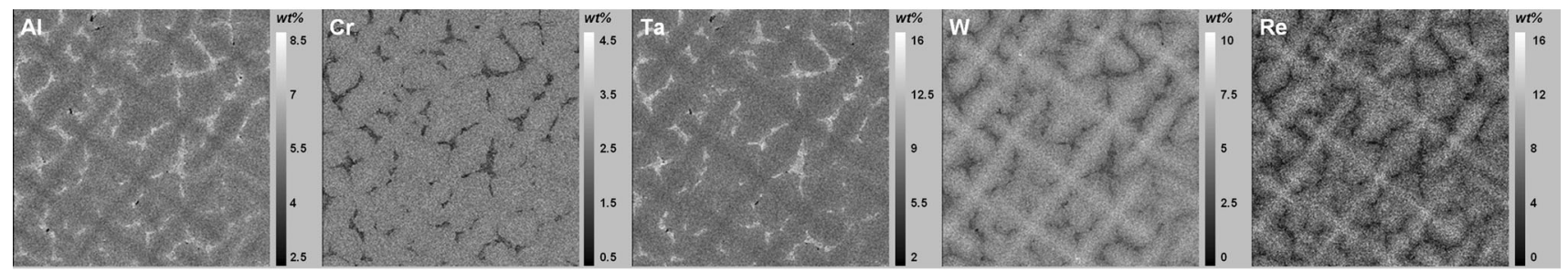

(c)

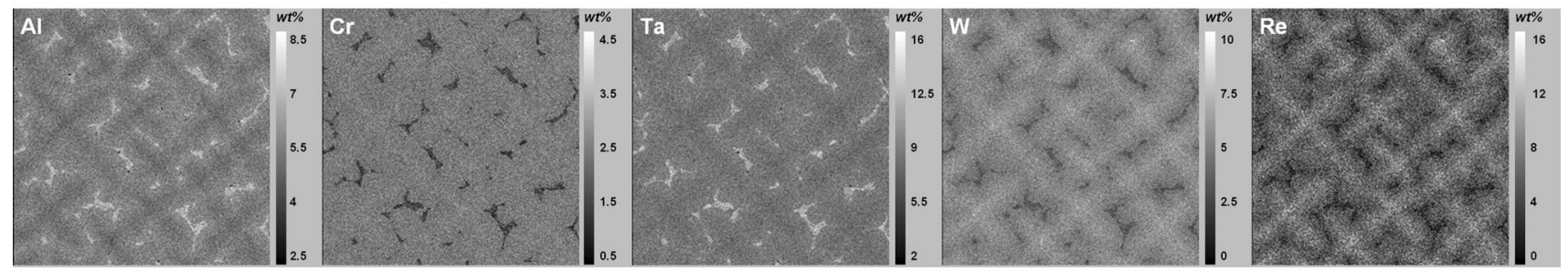

(d)

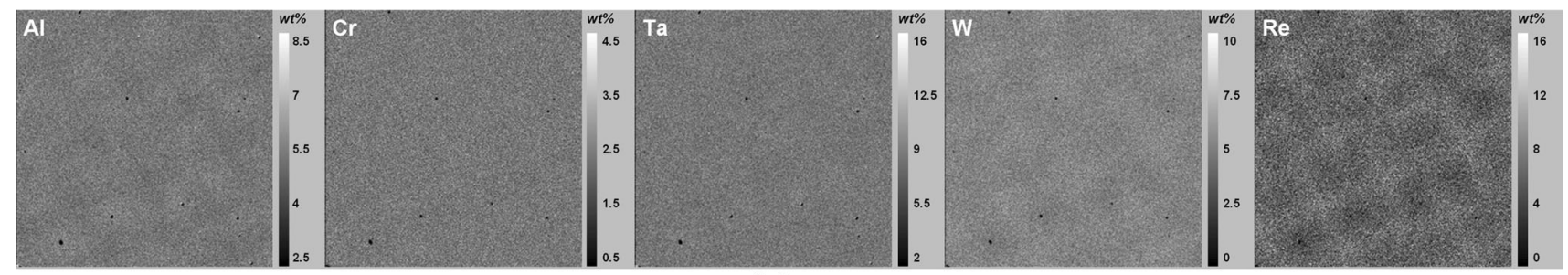

(e)

Fig. 9-Quantitative EPMA X-ray maps, area of each map is $1.25 \mathrm{~mm} \times 1.25 \mathrm{~mm}(a)$ as-cast condition and after various SHT steps $(b) 1627 \mathrm{~K}$ $\left(1354{ }^{\circ} \mathrm{C}\right) / 15 \mathrm{~min},(c) 1635 \mathrm{~K}\left(1362{ }^{\circ} \mathrm{C}\right) / 15 \mathrm{~min},(d) 1635 \mathrm{~K}\left(1362{ }^{\circ} \mathrm{C}\right) / 5 \mathrm{~h}$, and $(e) 1638 \mathrm{~K}\left(1365^{\circ} \mathrm{C}\right) / 20 \mathrm{~h}$.

when inspecting Figure 2. Significant diffusion and therefore homogenization would only be expected to occur when samples are subjected to a high enough temperature, and the chosen $\gamma^{\prime}$ solvus temperature provides a reasonable estimate. In practice, the temperatures were progressively raised with successive SHT steps, which should correspond to even greater degree of diffusion and homogenization.

In Figure 11, the as-cast condition is denoted by data points at time-zero, and with increasing time along the $x$-axes, the data points corresponds to the $1627 \mathrm{~K}(1354$ $\left.{ }^{\circ} \mathrm{C}\right) / 15$ minute, $1635 \mathrm{~K}\left(1362{ }^{\circ} \mathrm{C}\right) / 15$ minute, $1635 \mathrm{~K}$ $\left(1362{ }^{\circ} \mathrm{C}\right) / 5$ hour and $1638 \mathrm{~K}\left(1365^{\circ} \mathrm{C}\right) / 20$ hour steps respectively. Following the initial ramp-up and short hold at $1627 \mathrm{~K}\left(1354{ }^{\circ} \mathrm{C}\right) / 15$ minutes, the $T_{\mathrm{IM}}$ was quickly raised to $1641 \mathrm{~K}\left(1368{ }^{\circ} \mathrm{C}\right)$, accompanied by significant reduction in the inter-dendritic area fraction and compositional segregation. Given that the hold at $1627 \mathrm{~K}\left(1354{ }^{\circ} \mathrm{C}\right)$ was only for 15 minutes, significant homogenization must have occurred during both the heating up and the short hold stages contributing to the rapid increase in the $T_{\mathrm{IM}}$. After the $1635 \mathrm{~K}\left(1362^{\circ} \mathrm{C}\right) / 15$ 

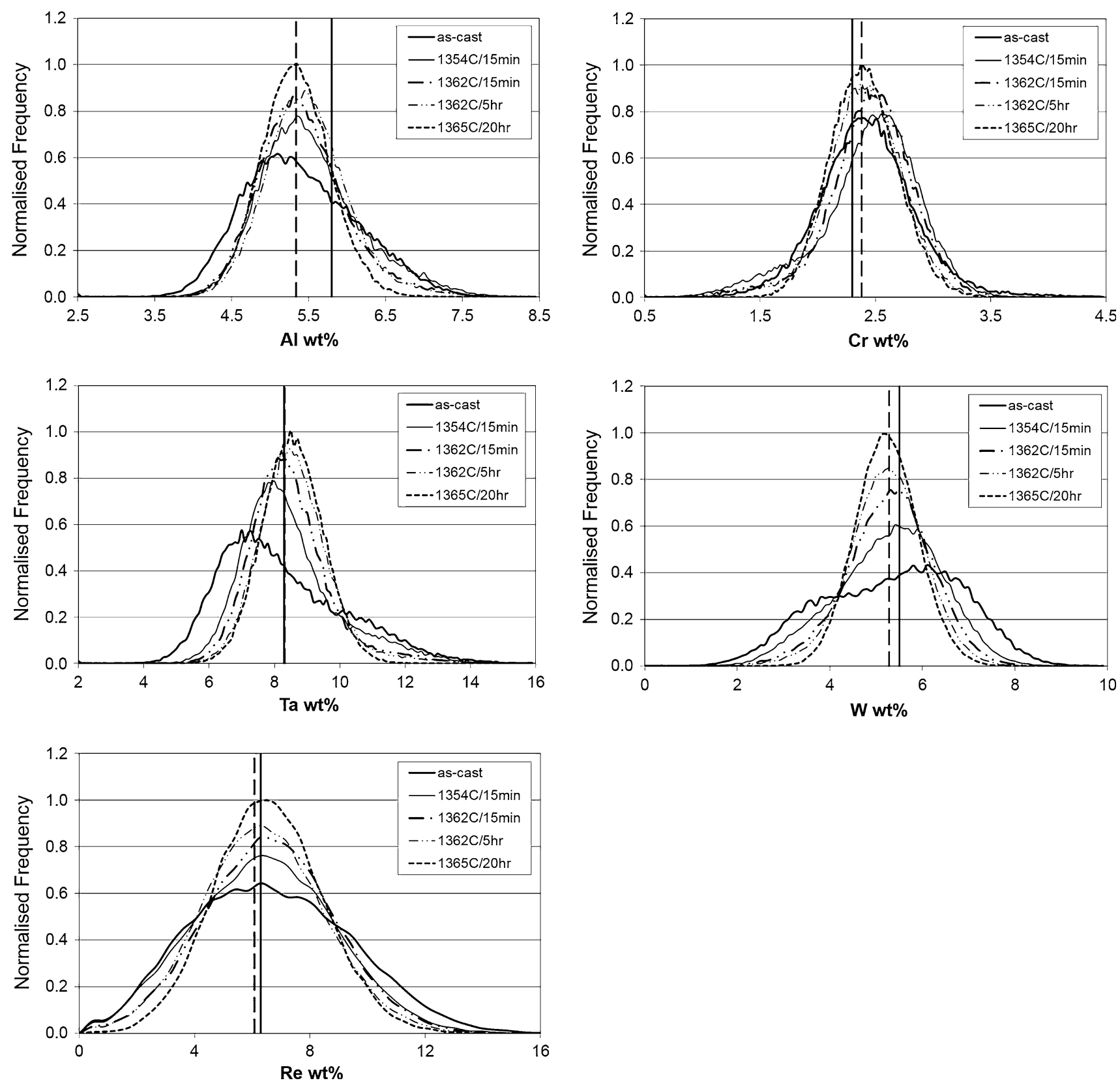

Fig. 10 - Histograms of normalized wt pct quantitative data showing the composition homogeneity of individual elements $\mathrm{Al}$, Cr, Ta, W, and Re with the progression of SHT. In each histogram, the solid vertical line denotes the nominal wt pct content of the element in the material while the dashed vertical line indicates the averages of the maximum peak positions (mode of the wt pct distribution).

Table V. Average and Standard Deviation (in Weight Percent) of Various Elements for the As-Cast Condition and After Various SHT Steps Obtained from Normalized EPMA X-ray Quantitative Data

\begin{tabular}{|c|c|c|c|c|c|}
\hline SHT Step & $C_{\mathrm{A} 1}$ & $C_{\mathrm{Cr}}$ & $C_{\mathrm{Ta}}$ & $C_{\mathrm{W}}$ & $C_{\mathrm{Re}}$ \\
\hline As-cast & $5.38 \pm 0.73$ & $2.42 \pm 0.41$ & $8.18 \pm 1.89$ & $5.29 \pm 1.49$ & $6.42 \pm 2.77$ \\
\hline $1627 \mathrm{~K}\left(1354^{\circ} \mathrm{C}\right) / 15 \mathrm{~min}$ & $5.51 \pm 0.66$ & $2.43 \pm 0.44$ & $8.40 \pm 1.49$ & $5.22 \pm 1.13$ & $6.17 \pm 2.46$ \\
\hline $1635 \mathrm{~K}\left(1362{ }^{\circ} \mathrm{C}\right) / 15 \mathrm{~min}$ & $5.40 \pm 0.57$ & $2.44 \pm 0.38$ & $8.41 \pm 1.23$ & $5.22 \pm 0.94$ & $6.37 \pm 2.27$ \\
\hline $1635 \mathrm{~K}\left(1362^{\circ} \mathrm{C}\right) / 5 \mathrm{~h}$ & $5.46 \pm 0.54$ & $2.38 \pm 0.35$ & $8.57 \pm 1.12$ & $5.17 \pm 0.82$ & $6.15 \pm 2.14$ \\
\hline $1638 \mathrm{~K}\left(1365^{\circ} \mathrm{C}\right) / 20 \mathrm{~h}$ & $5.31 \pm 0.45$ & $2.39 \pm 0.30$ & $8.51 \pm 0.93$ & $5.17 \pm 0.69$ & $6.34 \pm 1.87$ \\
\hline
\end{tabular}

minute step, the $T_{\mathrm{IM}}$ remained at $1641 \mathrm{~K}\left(1368{ }^{\circ} \mathrm{C}\right)$, despite the large decrease in inter-dendritic area fraction and the continuous reduction in compositional segregation compared to the preceding step. After the $1635 \mathrm{~K}\left(1362{ }^{\circ} \mathrm{C}\right) / 5$ hour step, there was further significant decrease in the inter-dendritic area fraction 


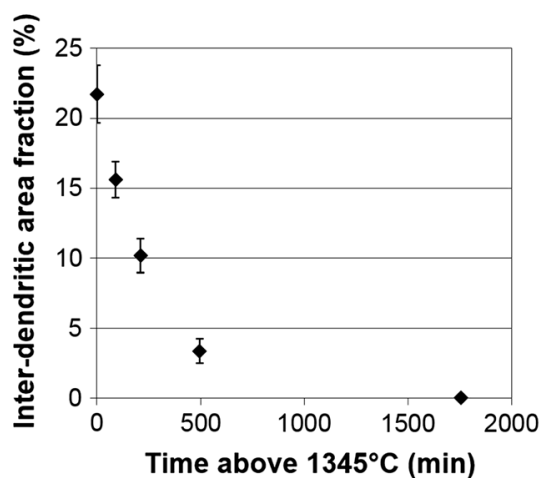

(a)

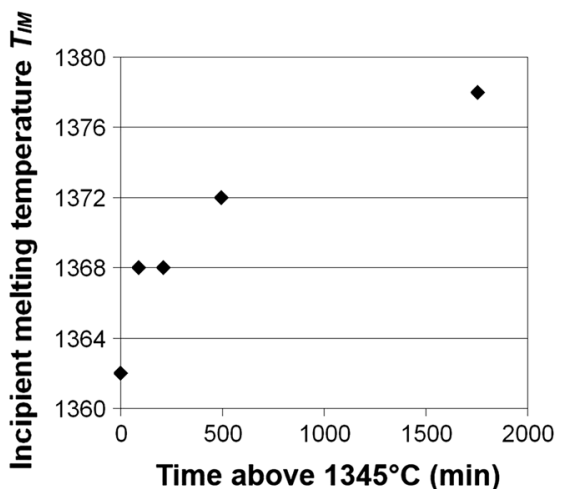

(b)

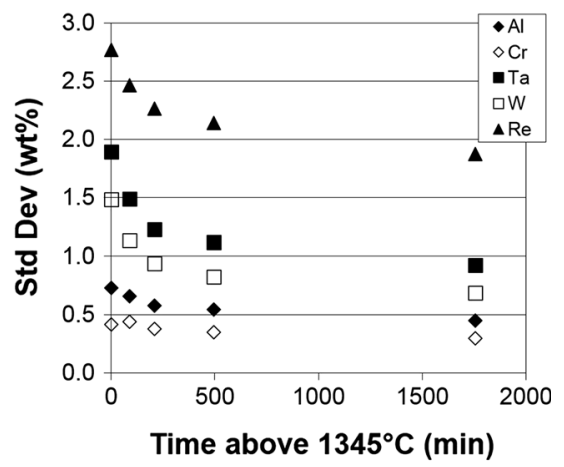

(c)

Fig. 11-Variation during the progression of SHT $(a)$ inter-dendritic area fraction, $(b) T_{\text {IM }}$, and $(c)$ standard deviation (wt pet) associated with composition measurements to indicate compositional homogeneity.

accompanied by further reduction in the compositional segregation compared to the previous step, however the $T_{\text {IM }}$ after this SHT step only increased marginally to $1645 \mathrm{~K}\left(1372{ }^{\circ} \mathrm{C}\right)$. After a substantial soak at the final $1638 \mathrm{~K}\left(1365^{\circ} \mathrm{C}\right) / 20$ hour step, the inter-dendritic area fraction was near-zero and the $T_{\mathrm{IM}}$ was further raised to $1651 \mathrm{~K}\left(1378{ }^{\circ} \mathrm{C}\right)$, however the decrease in standard deviations associated with the compositional segregation was relatively marginal compared to the prior step, which reflects the residual micro-segregation still observed after the final step.

The standard deviation data shown in Table $\mathrm{V}$ and Figure 11(c) are related to the partitioning behavior of the given element. The elements $\mathrm{Cr}, \mathrm{W}$, and Re partition to the solid and these partition more strongly in the order from $\mathrm{Cr} \rightarrow \mathrm{W} \rightarrow \mathrm{Re}^{[22]}$ Their partitioning coefficients are therefore greater than unity in ascending order and the standard deviations associated with the compositional segregation increases in magnitude from $\mathrm{Cr} \rightarrow \mathrm{W} \rightarrow \mathrm{Re}$. Likewise, for $\mathrm{Al}$ and $\mathrm{Ta}$ which partition to the liquid, Al partitions less strongly therefore the partitioning coefficient of $\mathrm{Al}$ is closer to unity. ${ }^{[22]}$ This was reflected in the lower standard deviations of $\mathrm{Al}$ compared to Ta. Elements which partition more strongly generally show a greater decrease in their standard deviations as the SHT progresses, i.e., these elements undergo more pronounced reduction in the strong segregation across the microstructure with the progression of SHT, e.g., W and Re compared to $\mathrm{Cr}$, and Ta compared to Al. However, the strong segregation of these elements (e.g., W, Re, and Ta) in the as-cast state, coupled with their low diffusivities in $\mathrm{Ni}$ result in their standard deviations being much higher compared to elements which partition less strongly (e.g., Al and $\mathrm{Cr}$ ) at a given point in the SHT.

From Figure 11, it is apparent that the inter-dendritic area fraction decreases exponentially in the early and intermediate stages of the SHT, up to the $1635 \mathrm{~K}(1362$ $\left.{ }^{\circ} \mathrm{C}\right) / 5$ hour step. However, corresponding changes in the $T_{\text {IM }}$ and compositional homogeneity only occur rapidly up to the $1627 \mathrm{~K}\left(1354{ }^{\circ} \mathrm{C}\right) / 15$ minute step and slow down significantly with subsequent SHT steps. This is in spite of the higher temperatures utilized in these subsequent SHT steps. Therefore, the homogenization of the lowest melting point areas appears to have slowed down and became more sluggish as the SHT progresses.

The key to explain the findings in this study may be found by rationalizing the evolution of the inter-dendritic microstructure, the dissolution of the inter-dendritic areas and the associated changes in the $T_{\mathrm{IM}}$, all of which are associated with, and driven by, the evolution of compositional homogeneity. The evolution of compositional homogeneity is in turn governed by local short-range diffusion, the driving force of which arises from the composition gradients. Therefore, the types of boundaries which exist in the microstructure and the corresponding composition gradients across these need to be considered. In the as-cast condition, three types of boundaries between the dendritic and inter-dendritic areas may exist as a result of the solidification sequence. These are (i) across the dendrite and fine $\gamma / \gamma^{\prime}$ areas, (ii) across the fine $\gamma / \gamma^{\prime}$ areas and coarse cellular $\gamma^{\prime}$ areas, and (iii) across the coarse cellular $\gamma^{\prime}$ areas and dendrite. These boundaries are schematically illustrated in Figure 12. The composition gradients across boundaries (i) and (ii) are continuous as these boundaries arise in accordance with the solidification sequence. However, strong composition gradients exist across boundaries of type (iii) where these boundaries separate the areas associated with the end of primary dendrite solidification (which immediately precedes the very start of the inter-dendritic region solidification) from the coarse cellular $\gamma^{\prime}$ inter-dendritic areas which were the last liquid to solidify and constitute the terminal stages of inter-dendritic solidification. ${ }^{[4]}$

The local melting temperature is governed by the local composition. In relation to Figure 12, the local compositions and the corresponding local melting temperatures are illustrated schematically in Figure 13 for the as-cast condition and after various SHT steps, in order to demonstrate the association between the changes in the composition homogeneity, microstructure and $T_{\mathrm{IM}}$ during the progression of SHT. The variation in the local concentrations of solute elements which partition 
(i)

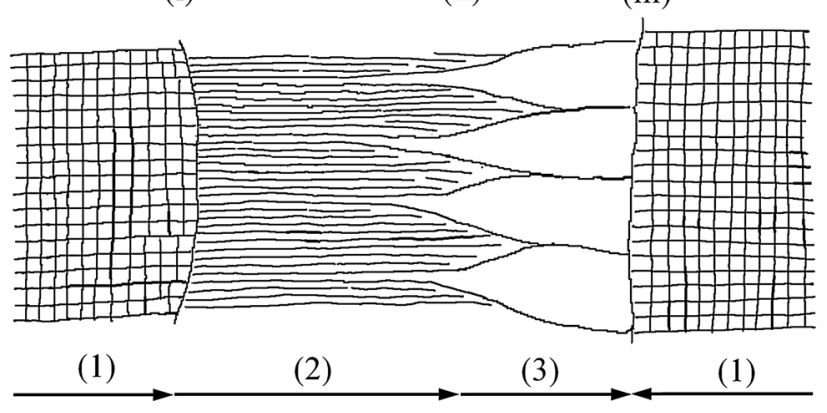

Boundaries

(i) $\gamma$ dendrite - fine $\gamma / \gamma^{\prime}$

(ii) fine $\gamma / \gamma^{\prime}$ - coarse cellular $\gamma^{\prime}$

(iii) $\gamma$ dendrite - coarse cellular $\gamma^{\prime}$

Solidification sequence

(1) Liquid $\rightarrow \gamma$ dendrite

(2) Liquid $\rightarrow$ fine $\gamma / \gamma^{\prime}$

(3) Liquid $\rightarrow$ coarse cellular $\gamma^{\prime}$

Fig. 12-Schematic illustration of the different types of boundaries in the as-cast microstructure of CMSX-10K.

to the liquid (e.g., Al, Ta) is illustrated. The illustration, based primarily on data obtained in this study, broadly represents the local compositions and the associated local melting temperatures in the various areas of the microstructure. The local composition and local melting temperature profiles of the SHT step under examination are shown with solid profile lines; while that of the preceding SHT step are shown with dashed profile lines. In addition, vertical lines mark the positions of the boundaries in the microstructure. The evolution of inter-dendritic area fraction is highlighted by the horizontal displacement of the vertical lines and also by arrows indicating the area fractions of the inter-dendritic constituents at the bottom of the local melting temperature diagrams, in accordance with the data in Table IV. On the local composition profiles, horizontal lines represent the local compositions. The degree of composition segregation is represented by the arrows to the right of the local composition diagrams in line with the wt pct distributions of solute elements shown in Figure 10. Conversely, horizontal lines shown in the local melting temperature profiles are associated with the thermo-physical characteristics (local melting point) of the various material conditions, in line with the data in Table III.

The boundaries illustrated in Figure 12 for the as-cast condition are shown in Figure 13(a), with their corresponding composition gradients. Strong composition gradients exist across the microstructure as a consequence of elemental partitioning during solidification, shown for e.g., Al. The lowest concentration is found at the start of solidification at dendrite cores and increases progressively reaching maximum levels at the end of solidification at the coarse cellular $\gamma^{\prime}$ inter-dendritic areas. The variation in local composition results in decreasing local melting temperatures from the highest level in the dendrite cores $\left(=T_{\text {liquidus }}\right)$ down to the lowest in the areas last to solidify. The $T_{\mathrm{IM}}$ is associated with the lowest melting point constituent; in the as-cast condition the $T_{\mathrm{IM}}$ of $1635 \mathrm{~K}\left(1362{ }^{\circ} \mathrm{C}\right)$ corresponds to melting of the coarse cellular $\gamma^{\prime}$ /narrow $\gamma$ channel areas which were the last areas to solidify.

After the $1627 \mathrm{~K}\left(1354{ }^{\circ} \mathrm{C}\right) / 15$ minute step, the wt pct distribution histograms shown in Figure 10 became pronouncedly narrowed compared to the as-cast condition. This implies a rapid reduction in the compositional segregation in areas with the highest and lowest concentrations of a given solute element. These areas are typically associated with dendrite cores and the coarse cellular $\gamma^{\prime}$ inter-dendritic areas which were the first and last areas to solidify respectively. In addition, in the as-cast condition, there were also significant composition gradients of solute elements across the type (iii) boundaries and EPMA X-ray maps have also shown very strong segregation of $\mathrm{Cr}$ at these boundaries. These result in rapid diffusion and homogenization, which leads to rapid flattening of the strong composition gradients across the type (iii) boundaries and the remnant coarse cellular $\gamma^{\prime}$ areas attaining near-equilibrium compositions with its surroundings. Homogenization in these various areas is shown by the flatter local composition profile highlighting the markedly reduced compositional segregation in Figure 13(b).

The DSC trace in Figure 2 shows a rapid increase in $T_{\mathrm{IM}}$ to $1641 \mathrm{~K}\left(1368^{\circ} \mathrm{C}\right)$ and a marked reduction in the magnitude of minor peak, i.e., a significant reduction in inter-dendritic area fraction as shown in Table IV, after the $1627 \mathrm{~K}\left(1354^{\circ} \mathrm{C}\right) / 15$ minute step. Therefore, homogenization of the strong compositional segregation at the type (iii) boundaries is accompanied by a rapid and considerable rise increase in $T_{\mathrm{IM}}$ as well as the ready dissolution of inter-dendritic areas as shown in Figure 13(b). The melting temperature of the remnant coarse cellular $\gamma^{\prime}$ areas becomes continuous between that of the adjacent dendrite areas and coarsened $\gamma / \gamma^{\prime}$ areas. However, the melting temperature of the remnant coarse cellular $\gamma^{\prime}$ is likely to be greater than the measured $T_{\mathrm{IM}}$, i.e., the measured $T_{\mathrm{IM}}$ of $1641 \mathrm{~K}\left(1368^{\circ} \mathrm{C}\right)$ after the 1627 $\mathrm{K}\left(1354{ }^{\circ} \mathrm{C}\right) / 15$ minute step is associated with coarsened $\gamma / \gamma^{\prime}$ rather than the remnant coarse cellular $\gamma^{\prime}$. This is due to the fact that $T_{\mathrm{IM}}$ remains unchanged at $1641 \mathrm{~K}$ (1368 $\left.{ }^{\circ} \mathrm{C}\right)$ after the $1635 \mathrm{~K}\left(1362{ }^{\circ} \mathrm{C}\right) / 15$ minute step where the majority of the remnant coarse cellular $\gamma^{\prime}$ has been dissolved. The substantial dissolution of inter-dendritic areas occurs at the lowest melting point coarse cellular $\gamma^{\prime}$ areas via inward growth of the advancing $\gamma$ dendrite into these areas. The reduced inter-dendritic area fraction and the advancing $\gamma$ dendrite front shown by the horizontal arrows highlighting the shift in microstructural boundaries are indicated in Figure 13(b).

The local composition and local melting temperature profiles after the $1635 \mathrm{~K}\left(1362{ }^{\circ} \mathrm{C}\right) / 15$ minute step is shown in Figure 13(c). The degree of homogenization is reduced due to the diminished composition gradients 


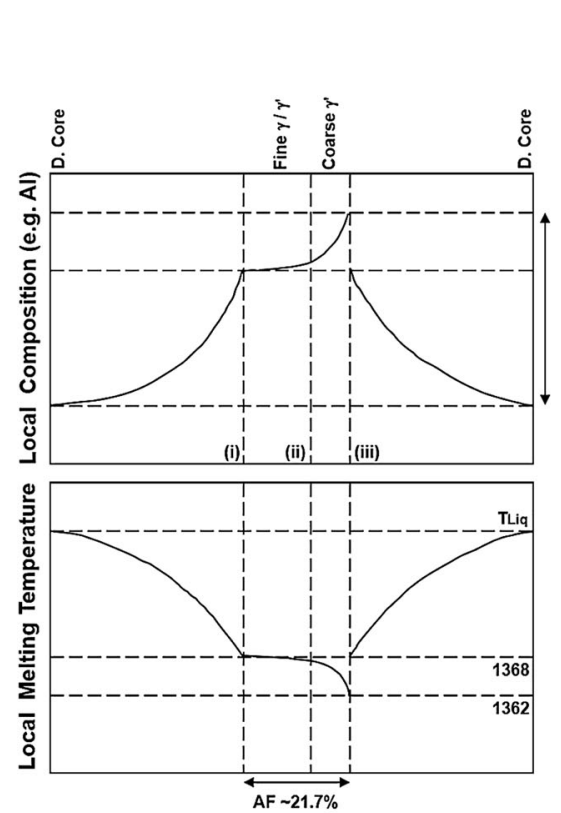

(a)

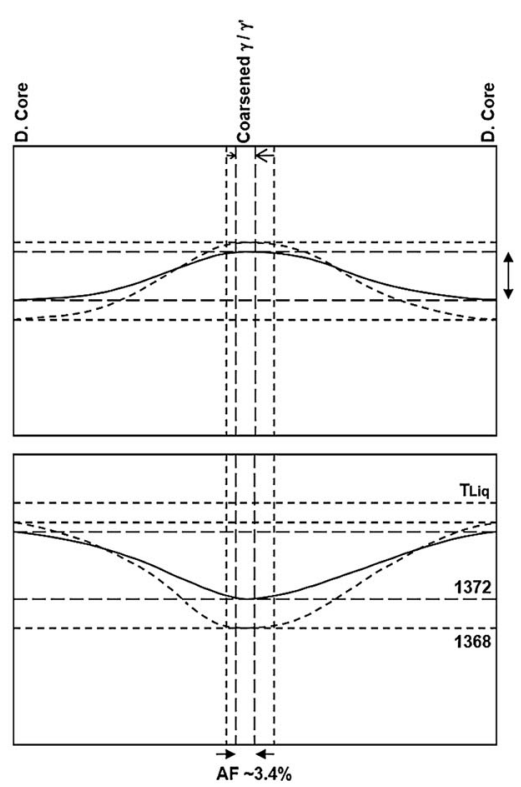

(d)

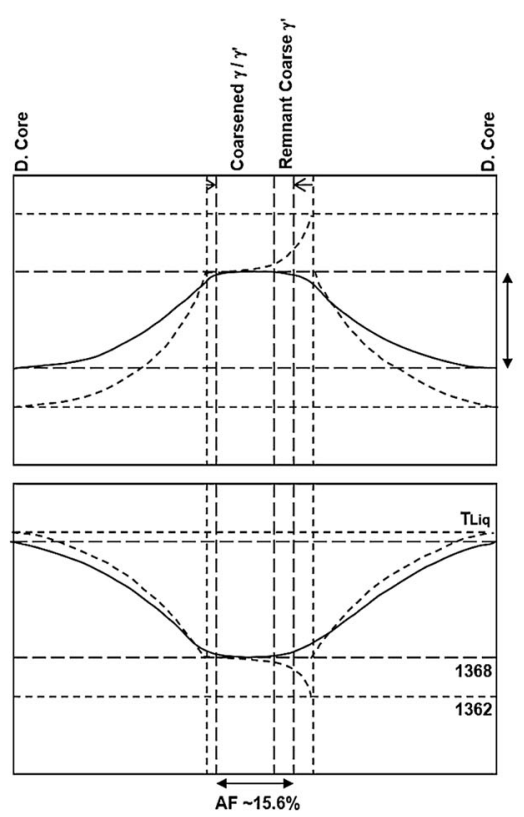

(b)

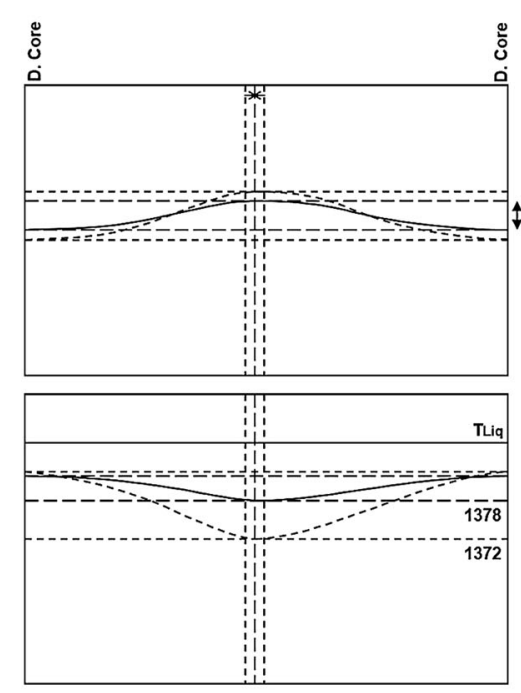

(e)

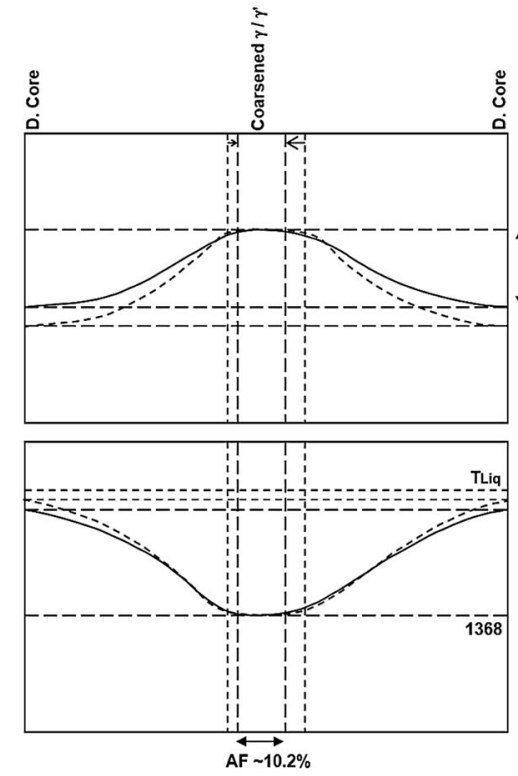

(c)

Fig. 13-Schematic illustration of the changes in local solute concentrations and corresponding local melting temperatures for samples in various conditions (a) as-cast, $(b) 1627 \mathrm{~K}\left(1354{ }^{\circ} \mathrm{C}\right) / 15 \mathrm{~min},(c) 1635 \mathrm{~K}\left(1362{ }^{\circ} \mathrm{C}\right) / 15 \mathrm{~min},(d) 1635 \mathrm{~K}\left(1362{ }^{\circ} \mathrm{C}\right) / 5 \mathrm{~h}$, and $(e) 1638 \mathrm{~K}\left(1365{ }^{\circ} \mathrm{C}\right) / 20 \mathrm{~h}$. The variation in the local solute concentration of solute element that partition to the liquid, e.g., $\mathrm{Al}$ or Ta, is illustrated. The local composition and local melting temperature profiles of the SHT step under examination are shown with solid profile lines; while that of the preceding SHT step are shown with dashed profile lines. Vertical lines mark the positions of the boundaries in the microstructure. Horizontal lines in the local composition profiles represent the local compositions while those in the local melting temperature profiles are associated with the thermo-physical characteristics (local melting point) for the various material conditions.

associated with the preceding step. The composition gradients become more gradual; there was little change in the inter-dendritic areas where the coarsened $\gamma / \gamma^{\prime}$ persists and most of the changes occurred within the dendrite areas. Despite this, considerable dissolution of the remnant coarse cellular $\gamma^{\prime}$ occurred in the inter-dendritic areas. There was no change in the $T_{\mathrm{IM}}$ after the
$1635 \mathrm{~K}\left(1362{ }^{\circ} \mathrm{C}\right) / 15$ minute step; this $T_{\mathrm{IM}}$ is associated with the coarsened $\gamma / \gamma^{\prime}$ areas.

Further substantial dissolution of inter-dendritic areas occurred after the $1635 \mathrm{~K}\left(1362{ }^{\circ} \mathrm{C}\right) / 5$ hour step as shown in Figure 13(d). The composition gradients become even more gradual across the microstructure which comprises mostly dendrite areas and a small 
extent of the coarsened $\gamma / \gamma^{\prime}$ areas. However, significant homogenization of these persistent coarsened $\gamma / \gamma^{\prime}$ areas with adjacent dendritic areas during the 5-hour hold at $1635 \mathrm{~K}\left(1362{ }^{\circ} \mathrm{C}\right)$ results in an increase in the $T_{\mathrm{IM}}$ to $1645 \mathrm{~K}\left(1372{ }^{\circ} \mathrm{C}\right)$.

Finally, after an extensive soak in the $1638 \mathrm{~K}$ (1365 $\left.{ }^{\circ} \mathrm{C}\right) / 20$ hour step, nearly all remaining coarsened $\gamma / \gamma^{\prime}$ inter-dendritic areas have been dissolved (near-zero levels) and the original inter-dendritic areas in the as-cast condition now comprise in-grown $\gamma$ dendrites, as shown in Figure 13(e). However, residual micro-segregation of solute elements still persists across the microstructure as indicated by data in Figure 10 and Table $\mathrm{V}$, and illustrated in the composition profile in Figure 13(e). Despite this, the near-complete dissolution of inter-dendritic constituents results in the $T_{\mathrm{IM}}$ which approaches the solidus temperature of fully homogenized CMSX-10K; $T_{\text {Solidus }} \approx 1651 \mathrm{~K}\left(1378{ }^{\circ} \mathrm{C}\right)$. This implies that complete dissolution of inter-dendritic areas does not necessarily correspond to the complete elimination of residual segregation; longer soak times may be required to completely eliminate residual segregation, but as processing costs scale with processing time, there is a need to assess the benefits associated with further reduction of the residual micro-segregation.

During the early stages of the SHT, coarsening of the fine $\gamma / \gamma^{\prime}$ morphology was observed which occurred in order to minimize the surface energies associated with the $\gamma / \gamma^{\prime}$ interfaces by minimizing the $\gamma / \gamma^{\prime}$ interfacial areas. However, this coarsening is not linked to the rapid changes in the $T_{\mathrm{IM}}$ observed in the early stages of the SHT. Firstly, these areas were formed at higher temperatures, and the coarsened $\gamma / \gamma^{\prime}$ morphology persisted until the intermediate/late stages of SHT. Their chemical compositions, and therefore their local melting temperatures are relatively stable and do not change significantly. In addition, the coarsened $\gamma / \gamma^{\prime}$ areas are typically associated with boundaries of types (i) and (ii) illustrated in Figure 12. The composition gradients across these boundaries are relatively gradual compared with those associated with type (iii) boundaries, hence the reduction in the segregation of solute elements across these boundaries occurs at a much slower rate, and is therefore unlikely to cause the large change in $T_{\text {IM }}$ observed in the early stages of the SHT.

During SHT, the dissolution of the coarse cellular $\gamma^{\prime}$ areas occurs much faster compared to the coarsened $\gamma / \gamma^{\prime}$ areas. The coarse cellular $\gamma^{\prime}$ areas are associated with strong composition gradients across type (iii) boundaries while the coarsened $\gamma / \gamma^{\prime}$ areas have been associated with more stable compositions and weaker composition gradients across type (i) and (ii) boundaries. In the intermediate SHT steps after the strong compositional gradients were reduced, greater compositional gradients are still expected across what was the original type (iii) boundaries compared to boundaries of type (i) and (ii), therefore the arrows in Figure 13 which indicate the movement of the advancing $\gamma$ dendrite front are moving faster into the coarse cellular $\gamma^{\prime}$ areas compared to the coarsened $\gamma / \gamma^{\prime}$ areas. The weak composition gradients within the dendrite areas and that within the inter-dendritic areas, as well as those across type (i) and (ii) boundaries also drive diffusion locally, resulting in the gradual flattening of the composition gradients within the dendrite area and the inter-dendritic areas and across the type (i) and (ii) boundaries with the progression of SHT, as shown in Figure 13. This is consistent with the composition homogeneity measurement data. The kinetics of diffusion and homogenization reduces as SHT progresses due to the weaker composition gradients, resulting in the need for higher temperatures and longer soak times toward the later stages of the SHT.

\section{CONCLUSIONS}

A detailed analysis of the response of the as-cast microstructure to solution heat treatment (SHT) has been carried out on a third-generation single-crystal nickel-based superalloy CMSX-10K. The following conclusions can be drawn from the current study:

1. In the early stages of the SHT, rapid flattening of the steep composition gradients associated with the last areas to solidify during casting occurred. The compositional segregation across these areas and the adjacent dendritic areas reduced significantly, which resulted in a rapid rise in the incipient melting temperature $T_{\mathrm{IM}}$ compared to the as-cast condition and a substantial dissolution of the coarse cellular $\gamma^{\prime}$ areas. Coarsening of the fine $\gamma / \gamma^{\prime}$ morphology also occurred in the early stages of the SHT.

2. In the subsequent SHT steps, the remnant coarse cellular $\gamma^{\prime}$ areas and coarsened $\gamma / \gamma^{\prime}$ areas dissolve more slowly due to significantly weaker composition gradients. The associated increase in the $T_{\mathrm{IM}}$ and the improvement in compositional homogeneity slow down despite the utilization of higher temperatures and longer soak times as the SHT progresses. However, notable dissolution of the inter-dendritic areas continues to occur.

3. The coarse cellular $\gamma^{\prime}$ areas dissolve more readily compared to the coarsened $\gamma / \gamma^{\prime}$ areas; therefore, toward the intermediate stages of SHT, the remnant coarse cellular $\gamma^{\prime}$ areas are completely dissolved and the lowest melting point areas are now associated with the coarsened $\gamma / \gamma^{\prime}$ areas. The slowdown in the pace of the $T_{\mathrm{IM}}$ increase is therefore due to the persistent coarsened $\gamma / \gamma^{\prime}$ areas which are significantly harder to dissolve in the presence of progressively weaker composition gradients as the SHT progresses.

4. It is only after the more prolonged soaks in the 1635 $\mathrm{K}\left(1362{ }^{\circ} \mathrm{C}\right) / 5$ hour and $1638 \mathrm{~K}\left(1365^{\circ} \mathrm{C}\right) / 20$ hour steps that the local compositional segregation are markedly reduced and the local melting temperatures of these areas are pronouncedly increased. After the final SHT step at $1638 \mathrm{~K}\left(1365{ }^{\circ} \mathrm{C}\right) / 20$ hour, residual micro-segregation could still be detected across the microstructure even though most of the persistent coarsened $\gamma / \gamma^{\prime}$ areas were dissolved. Despite this, the $T_{\mathrm{IM}}$ approaches the solidus temperature of the material after the final SHT step. 


\section{ACKNOWLEDGMENTS}

The authors would like to acknowledge funding through the EPSRC/Rolls-Royce Strategic Partnership (EP/H500375/1 and EP/M005607/1). The authors also wish to express their appreciation to Dr. Chris Hayward at the School of Geosciences, University of Edinburgh for carrying out the EPMA composition measurements and to Mr. Kevin Roberts of Dept. of Materials Science and Metallurgy for his assistance in carrying out the solution heat treatment runs. Requests for access to the underlying research data should be directed to the corresponding author and will be considered against commercial interests and data protection.

\section{OPEN ACCESS}

This article is distributed under the terms of the Creative Commons Attribution 4.0 International License (http://creativecommons.org/licenses/by/4.0/), which permits unrestricted use, distribution, and reproduction in any medium, provided you give appropriate credit to the original author(s) and the source, provide a link to the Creative Commons license, and indicate if changes were made.

\section{REFERENCES}

1. G.L. Erickson: J. Met., 1995, vol. 47, pp. 36-39.

2. G.E. Fuchs: Mater Sci. Eng. A, 2001, vol. 300A, pp. 52-60.

3. M.S.A. Karunaratne, D.C. Cox, P. Carter, and R.C. Reed: in Superalloys 2000, R.C. Reed, T.M. Pollock, R.D. Kissinger, R.R. Bowman, K.A. Green, M. McLean, S. Olson, and J.J. Schirra, eds., TMS, Warrendale, PA, 2000, pp. 263-72.
4. H.T. Pang, H.B. Dong, R. Beanland, H.J. Stone, C.M.F. Rae, P.A. Midgley, G. Brewster, and N. D'Souza: Metall. Trans. A, 2009, vol. 40A, pp. 1660-69.

5. N. D'Souza and H.B. Dong: Scripta Mater., 2007, vol. 56, pp. $41-44$

6. S.M. Seo, J.-H. Lee, Y.-S. Yoo, C.-Y. Jo, H. Miyahara, and K. Ogi: in Superalloys 2008, R.C. Reed, K.A. Green, P. Caron, T. Gabb, M.G. Fahrmann, E.S. Huron, and S.A. Woodward, eds., TMS, Warrendale, PA, 2008, pp. 277-86.

7. N. Warnken, D. Ma, M. Mathes, and I. Steinbach: Mater. Sci. Eng. A, 2005, vols. 413-414, pp. 267-71.

8. C. Walter, B. Hallstedt, and N. Warnken: Mater. Sci. Eng. A, 2005, vol. 397, pp. 385-90.

9. R.M. Kearsey, J.C. Beddoes, P. Jones, K.M. Jansaalu, W.T. Thompson, and P. Au: in Superalloys 2004, K.A. Green, T.M. Pollock, H. Harada, T.E. Howson, R.C. Reed, J.J. Schirra, and S. Walston, eds., TMS, Warrendale, PA, 2004, pp. 801-10.

10. C. Schulze and M. Feller-Kniepmeier: Mater. Sci. Eng. A., 2000, vol. A281, pp. 204-12.

11. J. Coakley, R.C. Reed, J.L.W. Warwick, K.M. Rahman, and D. Dye: Acta Mater., 2012, vol. 60, pp. 2729-38.

12. T.M. Pollock and A.S. Argon: Acta Metall. Mater., 1992, vol. 40, pp. $1-30$.

13. N Warnken, H Larrson, and RC Reed: Mater. Sci. Technol, 2009, vol. 25, pp. 179-85.

14. S.L. Semiatin, R.C. Kramb, R.R. Turner, F. Zhang, and M.M. Anthony: Scripta Met., 2004, vol. 51, pp. 491-95.

15. B.C. Wilson, J.A. Hickman, and G.E. Fuchs: JOM, 2003, vol. 55, pp. 35-40.

16. L. Chapman: J. Mater. Sci., 2004, vol. 39, pp. 7229-36.

17. D.L. Sponseller: in Superalloys 1996, R.D. Kissinger, D.J. Deye, D.L. Anton, A.D. Cetel, M.V. Nathal, T.M. Pollock, and D. Woodford, eds., TMS, Warrendale, PA, 1996, pp. 259-66.

18. S.J.B. Reed and A. Buckley: Mikrochim. Acta (Suppl.), 1996, vol. 13, pp. 479-83.

19. W.J. Boettinger and U.R. Kattner: Metall. Trans. A, 2002, vol. 33A, pp. 1779-94.

20. H.T. Pang, L. Zhang, R.A. Hobbs, H.J. Stone, and C.M.F. Rae: Metall. Trans. A, 2012, vol. 43A, pp. 3264-82.

21. J.O. Andersson, T. Hellander, L. Hoglund, P. F. Shi, and B. Sundman: CALPHAD, 2002, vol. 26, pp. 273-312 (TTNi8 database: http://www.thermocalc.com/).

22. R.A. Hobbs, S. Tin, and C.M.F. Rae: Metall. Trans. A, 2005, vol. $36 \mathrm{~A}$, pp. $2761-73$. 